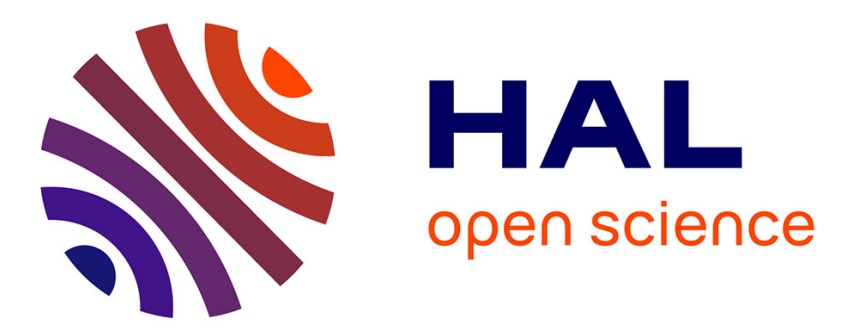

\title{
Concomitant initiation of radical and cationic polymerisations using new copper complexes as photoinitiators: synthesis and characterisation of acrylate/epoxy interpenetrated polymer networks
}

Alexandre Mau, Céline Dietlin, Frédéric Dumur, Jacques Lalevée

\section{To cite this version:}

Alexandre Mau, Céline Dietlin, Frédéric Dumur, Jacques Lalevée. Concomitant initiation of radical and cationic polymerisations using new copper complexes as photoinitiators: synthesis and characterisation of acrylate/epoxy interpenetrated polymer networks. European Polymer Journal, 2021, 152, pp.110457. 10.1016/j.eurpolymj.2021.110457 . hal-03207506

\author{
HAL Id: hal-03207506 \\ https://hal.science/hal-03207506
}

Submitted on 25 Apr 2021

HAL is a multi-disciplinary open access archive for the deposit and dissemination of scientific research documents, whether they are published or not. The documents may come from teaching and research institutions in France or abroad, or from public or private research centers.
L'archive ouverte pluridisciplinaire HAL, est destinée au dépôt et à la diffusion de documents scientifiques de niveau recherche, publiés ou non, émanant des établissements d'enseignement et de recherche français ou étrangers, des laboratoires publics ou privés. 


\title{
Concomitant initiation of radical and cationic polymerisations using new copper complexes as photoinitiators: synthesis and characterisation of acrylate/epoxy interpenetrated polymer networks
}

\author{
Alexandre $\mathrm{Mau}^{\mathrm{a}}{ }^{\mathrm{b}}$, Céline Dietlin $^{\mathrm{ab}}$, Frédéric Dumur ${ }^{\mathrm{d}}$ and Jacques Lalevée*a b \\ ${ }^{a}$ Université de Haute-Alsace, CNRS, IS2M UMR 7361, F-68100 Mulhouse, France \\ ${ }^{\mathrm{b}}$ Université de Strasbourg, France \\ ${ }^{c}$ Aix Marseille Univ, CNRS, ICR, UMR 7273, F-13397 Marseille, France
}

* Corresponding author: jacques.lalevee@uha.fr (J. L.)

\begin{abstract}
Two new copper complexes were investigated in three-component visible light photoinitiating system for both radical and cationic polymerisation under air. Their reactivity and efficiency have been compared with that of a highly efficient photoredox catalyst G1. The formation of acrylate/epoxy interpenetrated polymer networks were successfully performed through concomitant initiation of radical and cationic polymerisation with low copper complex content upon either LED@405nm or LED@455 nm irradiations. Several characterisations of the acrylate/epoxy IPNs final properties, such as the mechanical properties, adhesion properties, shrinkage and swelling, indicated the possibilities to adapt or tune their properties compared to radical polymerisation of TMPTA.
\end{abstract}

\section{Introduction}

Polymerisation initiated upon light exposure is a process widely used industrially. Various applications such as medicine, dentistry [1], adhesives, coatings [2], composites [3], laser writing and 3D printing [4] are already based on this process. However, a drawback of industrial applications of photopolymerisation is the use of UV light which is a source of safety issues [5]. With the development of affordable, compact, and safe visible irradiation sources such as light-emitting diodes (LEDs), the development of photoinitiating systems working under visible light has remained an important topic of research.

Over the past decades, few photoinitiating systems capable of initiating both the radical polymerisation and the cationic polymerisation have been developed [3,6-9]. Among them, a copper complex called G1 was developed as a highly efficient photoinitiator for the radical and cationic polymerisation under visible LED irradiation [3]. Photoinitiating systems based on G1 can produce reactive species (radicals and cations) following a catalytic cycle through successive reactions. Considering the efficiency of G1, other copper complexes are still developed in the aim to concomitantly initiate both radical and cationic polymerisations. 
Interpenetrated polymer networks (IPNs) are a combination of two polymers possessing a network form and constitute an interesting class of materials [10]. Indeed, they can be obtained by polymerisation of two monomers through two different mechanisms (e.g. radical polymerisation, cationic polymerisation or anionic polymerisation). In the past, they were usually obtained by an in-situ generation approach with the UV irradiation of a monomer blend containing photoinitiators as shown in Scheme 1. Usually, two photoinitiating systems are involved in this process, one for initiating each polymerisation [11]. Moreover, the main interest of IPNs is that they combine the properties or the two polymers networks which could allow some possibilities of properties tuning. However, to date, few characterisations of IPNs properties are reported in the literature.
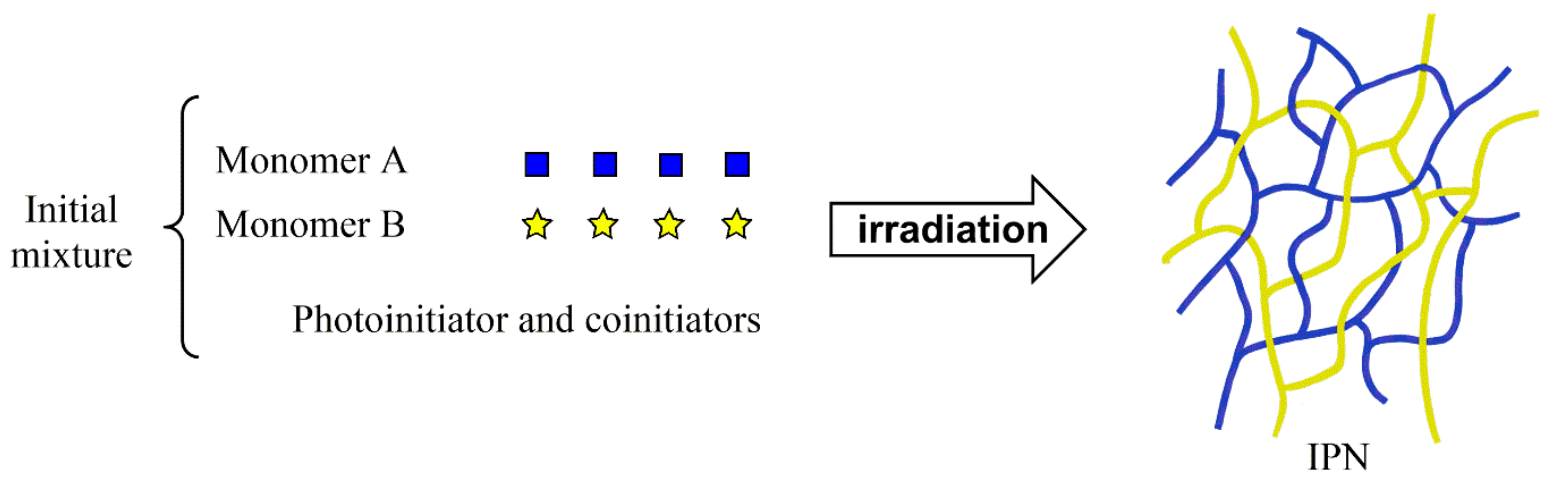

Scheme 1: In-situ synthesis of interpenetrated polymer networks by photopolymerisation

In this work, two new copper complexes, $\mathrm{CuA}$ and $\mathrm{CuB}$ (Scheme 1), were investigated as photoinitiators upon irradiation with visible light-emitting diodes (LEDs) for the radical polymerisation of acrylate, the cationic polymerisation of epoxide and the formation of acrylate/epoxy interpenetrating polymer networks. The efficiency of $\mathrm{CuA}$ or $\mathrm{CuB}$ based photoinitiating systems $\mathrm{Cu}$ /iodonium salt (Iod)/ethyl 4-(dimethylamino)benzoate (EDB) was investigated and compared to the highly efficient system G1/Iod/EDB which was used as a reference. Moreover, these systems were studied for the in-situ generation of IPNs by the simultaneous initiation of both radical and cationic polymerisations with only one photoinitiating system. To evidence the interest of acrylate/epoxy IPNs compared to TMPTA, several IPNs final properties were investigated. Characteristics such as the mechanical properties, adhesion properties, shrinkage, swelling and post-curing migration were also examined.

\section{Experimental section}

\subsection{Chemical compounds}

\subsubsection{Compounds used as photoinitiators}

The investigated copper complexes $\mathrm{CuA}$ and $\mathrm{CuB}$, presented in Scheme 2 were synthesized according to the procedure depicted below. The copper complex G1 was synthesized according to the procedure reported in [9]. 


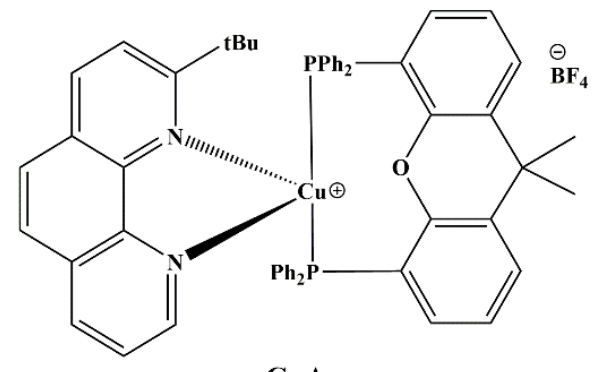

$\mathrm{CuA}$



CuB

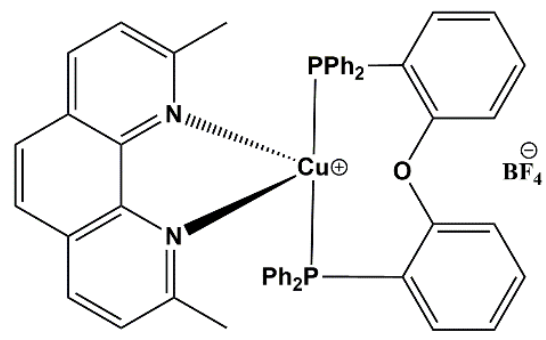

G1

Scheme 2: Investigated copper complexes $\mathrm{CuA}$ and $\mathrm{CuB}$ and benchmark copper complex G1

2-(Tert-butyl)-1,10-phenanthroline was synthesized as previously reported in the literature, without modification and in similar yields [12].

Synthesis of 2-(tert-butyl)-1,10-phenanthroline- $\left.\kappa N^{1}, \kappa N^{10}\right]\left[1,1^{\prime}-(9,9-\right.$ dimethyl- $9 H$-xanthene4,5-diyl)bis[1,1-diphenylphosphine- $\kappa P]] \operatorname{copper}(\mathrm{I})$ tetrafluoroborate $(\mathrm{CuA})$

A mixture of $\left[\mathrm{Cu}\left(\mathrm{CH}_{3} \mathrm{CN}\right)_{4}\right] \mathrm{BF}_{4}(310 \mathrm{mg}, 1 \mathrm{mmol})$ and 4,5-bis(diphenylphosphino)-9,9dimethylxanthene (Xantphos) (578 mg, $1 \mathrm{mmol}, \mathrm{M}=578.62 \mathrm{~g} / \mathrm{mol}$ ) was dissolved in $200 \mathrm{~mL}$ of dichloromethane. The solution was allowed to stir at room temperature for $1 \mathrm{~h}$ and a solution of 2-(tert-butyl)-1,10-phenanthroline (236 mg, $1 \mathrm{mmol}, \mathrm{M}=236.32 \mathrm{~g} / \mathrm{mol}$ ) in dichloromethane $(20 \mathrm{~mL})$ was added in one portion. The resulting solution was stirred overnight. The solvent was partially removed under reduced pressure. During evaporation, a precipitate formed. It was filtered off, washed several times with pentane and dried under vacuum ( $88 \%$ yield). ${ }^{1} \mathrm{H}$ NMR $\left(400 \mathrm{MHz}, \mathrm{CDCl}_{3}\right) \delta 8.54-8.49(\mathrm{~m}, 2 \mathrm{H}), 7.97(\mathrm{dt}, J=12.0,8.7 \mathrm{~Hz}, 3 \mathrm{H}), 7.73-7.66(\mathrm{~m}, 2 \mathrm{H})$, $7.57-7.48(\mathrm{~m}, 2 \mathrm{H}), 7.27-7.15(\mathrm{~m}, 6 \mathrm{H}), 7.10-6.98(\mathrm{~m}, 12 \mathrm{H}), 6.86(\mathrm{~d}, J=4.5 \mathrm{~Hz}, 4 \mathrm{H}), 6.76$ $-6.70(\mathrm{~m}, 2 \mathrm{H}), 1.84$ (s, 3H), 1.77 (s, 3H), 1.27 (d, $J=20.4 \mathrm{~Hz}, 9 \mathrm{H}) ;{ }^{13} \mathrm{C} \mathrm{NMR}\left(75 \mathrm{MHz}, \mathrm{CDCl}_{3}\right)$ $\delta 170.07,154.65,154.57,147.61,138.84,138.44,133.58,133.47,133.37,132.64,132.54$, $132.44,130.91,130.86,130.65,130.23,129.98,129.89,128.74,128.68,128.64,128.62$, 128.58, 128.20, 127.86, 127.33, 126.53, 125.29, 124.29, 122.38, 120.13, 30.81, 30.77, 30.74, 30.27, 27.26; ${ }^{19} \mathrm{~F}$ NMR $\left(376 \mathrm{MHz}, \mathrm{CDCl}_{3}\right) \delta-154.03 ;{ }^{31} \mathrm{P}$ NMR $\left(162 \mathrm{MHz}, \mathrm{CDCl}_{3}\right) \delta-12.19$; HRMS (ESI MS) m/z: theor: 877.2532 found: $877.2538\left(\mathrm{M}^{+.}\right.$detected)

Synthesis of (2-(tert-butyl)-1,10-phenanthroline- $\left.\kappa N^{1}, \kappa N^{10}\right)\left[1,1^{\prime}\right.$-(oxydi-2,1-phenylene) bis[1,1diphenylphosphine- $\kappa P]$ copper(I) tetrafluoroborate $\mathrm{CuB}$

A mixture of $\left[\mathrm{Cu}\left(\mathrm{CH}_{3} \mathrm{CN}\right)_{4}\right] \mathrm{BF}_{4}(310 \mathrm{mg}, 1 \mathrm{mmol})$ and bis[2-(diphenylphosphino)phenyl]ether (DPEPhos) (540 mg, $1 \mathrm{mmol}$ ) in $200 \mathrm{~mL}$ of dichloromethane was stirred at room temperature for $1 \mathrm{~h}$ and then treated with a solution of 2-(tert-butyl)-1,10-phenanthroline (236 mg, $1 \mathrm{mmol}$, $\mathrm{M}=236.32 \mathrm{~g} / \mathrm{mol}$ ) in $50 \mathrm{~mL}$ of dichloromethane. The resulting solution was stirred overnight. The solvent was partially removed under reduced pressure. During evaporation, a precipitate formed. It was filtered off, washed several times with pentane and dried under vacuum $(81 \%$ 
yield). ${ }^{1} \mathrm{H}$ NMR $\left(400 \mathrm{MHz}, \mathrm{CDCl}_{3}\right) \delta 8.39(\mathrm{~d}, J=8.2 \mathrm{~Hz}, 1 \mathrm{H}), 8.34(\mathrm{~d}, J=8.5 \mathrm{~Hz}, 1 \mathrm{H}), 8.25$ $(\mathrm{d}, J=4.8 \mathrm{~Hz}, 1 \mathrm{H}), 7.95(\mathrm{~s}, 2 \mathrm{H}), 7.75(\mathrm{~d}, J=8.5 \mathrm{~Hz}, 1 \mathrm{H}), 7.41-7.13(\mathrm{~m}, 12 \mathrm{H}), 7.03$ (dd, $J=$ 16.0, $8.4 \mathrm{~Hz}, 6 \mathrm{H}), 6.98-6.86(\mathrm{~m}, 7 \mathrm{H}), 6.58(\mathrm{~s}, 4 \mathrm{H}), 1.38(\mathrm{~s}, 9 \mathrm{H}) ;{ }^{13} \mathrm{C} \mathrm{NMR}\left(75 \mathrm{MHz}, \mathrm{CDCl}_{3}\right)$ $\delta 169.83,157.46,157.38,157.30,148.72,138.37,137.92,134.25,133.61,132.34,130.35$, $129.84,129.46,128.78,128.44,127.83,127.52,126.33,125.23,123.89,123.83,123.70$, $121.84,119.53,37.79,30.72,30.68,30.65 ;{ }^{19} \mathrm{~F} \mathrm{NMR}\left(376 \mathrm{MHz}, \mathrm{CDCl}_{3}\right) \delta-153.82 ;{ }^{31} \mathrm{P} \mathrm{NMR}$ $\left(162 \mathrm{MHz}, \mathrm{CDCl}_{3}\right) \delta-13.46$; HRMS (ESI MS) m/z: theor: 837.2219 found: $837.2215\left(\mathrm{M}^{+}\right.$ detected).

\subsubsection{Other chemical compounds}

Bis-(4-tert-butylphenyl)iodonium hexafluorophosphate (Iod; SpeedCure 938), ethyl 4(dimethylamino)benzoate (EDB; SpeedCure EDB) were obtained from Lambson Ltd (UK). Trimethylolpropane triacrylate (TMPTA) and (3,4-epoxycyclohexane)methyl-3,4epoxycyclohexylcarboxylate (EPOX; Uvacure 1500) were obtained from Allnex and used as benchmark monomers for radical and cationic photopolymerisation, respectively (Scheme 3). Dichloromethane (DCM, purity $\geq 99 \%$ ) was used as the solvent.

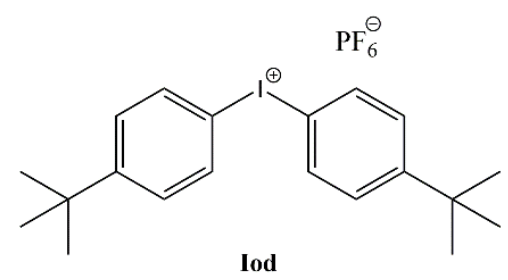<smiles>CCOC(=O)c1ccc(N(C)C)cc1</smiles>
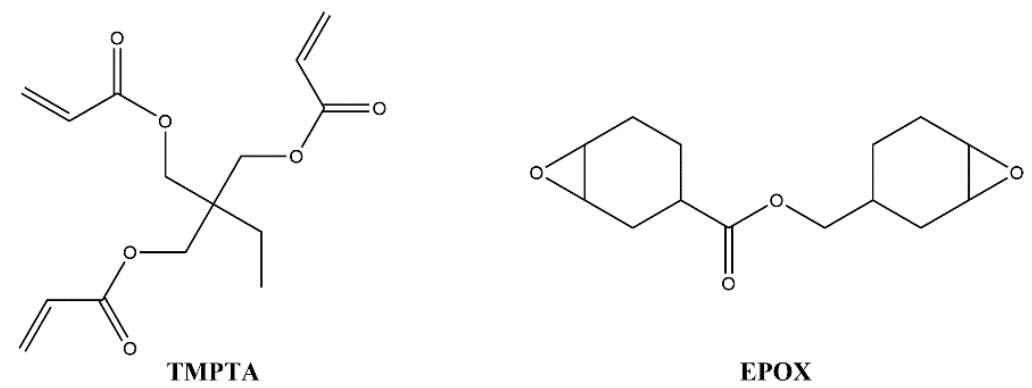

EPOX

Scheme 3: Chemical structures of additives and monomers

\subsection{UV-visible absorption spectroscopy}

UV-visible absorption spectra were acquired in either DCM or acetonitrile in a quartz cell at room temperature using a Jasco V-750 spectrophotometer. The molar extinction coefficients were determined using the Beer-Lambert law with experimental data obtained on solutions of known concentrations.

\subsection{Steady-state fluorescence}

Fluorescence spectra were acquired in a quartz cell at room temperature using a JASCO ${ }^{\circ}$ FP750 spectrofluorometer. Excitation and emission spectra were recorded in DCM in a quartz cell. 


\subsection{Photopolymerisation kinetics (FTIR)}

Experimental conditions for each photosensitive formulation are given in the captions of the figures. The weight percent of the photoinitiating system is calculated from the monomer content. The photoinitiator concentrations in each photosensitive formulation were chosen to ensure the same light absorption at $405 \mathrm{~nm}$.

All polymerisations were performed at ambient temperature $\left(21-25^{\circ} \mathrm{C}\right)$ and irradiation was started at $\mathrm{t}=10 \mathrm{~s}$. Two LEDs, having an intensity around $50 \mathrm{~mW} \cdot \mathrm{cm}^{-2}$ at the sample position, were used for the photopolymerisation experiments: a LED@ 405 nm (M405L3 - Thorlabs) and a LED@455 nm (M455L3 - Thorlabs) centred at $452 \mathrm{~nm}$. Their emission spectra are already available in the literature [13].

A Jasco 4100 real-time Fourier transform infrared spectrometer (RT-FTIR) was used to follow the conversion of the acrylate functions of the TMPTA monomer and of the epoxide group of EPOX. The photocurable formulations were deposited on a polypropylene film inside a $1.4 \mathrm{~mm}$ thick mould under air. The evolutions of the $\mathrm{C}=\mathrm{C}$ double bond band and the epoxide group band were continuously followed from 6117 to $6221 \mathrm{~cm}^{-1}$ and from 3710 to $3799 \mathrm{~cm}^{-1}$ respectively.

\subsection{Dynamical mechanical analyses}

The dynamical mechanical behaviour of the samples after curing was followed on a MettlerToledo DMA/SDTA 861 viscoanalyser. A polymer (2.2 mm thick, $12 \mathrm{~mm}$ diameter) were prepared by irradiation with the LED@405nm, centred at $405 \mathrm{~nm}$, having an intensity around $120 \mathrm{~mW} \cdot \mathrm{cm}^{-2}$ at the sample position. To ensure a consistent cylinder geometry, the samples were polished after irradiation. Storage and loss modulus ( $G^{\prime}$ and $G^{\prime \prime}$ ) and also $\tan \delta$ were registered as a dependence on temperature ranging from -50 to $200^{\circ} \mathrm{C}$ using a $2{ }^{\circ} \mathrm{C} \cdot \mathrm{min}^{-1}$ heating rate and a frequency of $1 \mathrm{~Hz}$.

\subsection{Differential scanning calorimetry}

Differential scanning calorimetry (DSC) studies of different samples after curing were carried out in an aluminium crucible with a Mettler-Toledo DSC differential scanning calorimeter. The temperature range was from -50 to $200{ }^{\circ} \mathrm{C}$ with a heating rate of $10{ }^{\circ} \mathrm{C} . \mathrm{min}^{-1}$ under nitrogen flow

\subsection{Adhesion properties}

The materials were prepared by bonding two epoxy substrates (bonded surface $=250 \mathrm{~mm}^{2}$ ). Curing of the different formulations was realised by frontal polymerisation while irradiating the resins during 180s with the LED@405nm centred at $405 \mathrm{~nm}$, having an intensity around $120 \mathrm{~mW} \cdot \mathrm{cm}^{-2}$ at the sample position.

The lap shear strength tests were carried out on a modernised Zwick INSTON 4505 dynamometer. The specimens were gripped by two screw-type flat-plate grips and pulled at a shear rate of $10 \mathrm{~mm} \cdot \mathrm{min}^{-1}$ with a $100 \mathrm{kN}$ cell of force.

2.8 Determination of the volumetric shrinkage

Volumetric shrinkage (S) was determined by calculating the density of the different formulation before $\left(\rho_{\text {resin }}\right)$ and after curing ( $\left.\rho_{\text {polymer }}\right)$ using the Equation (1):

$$
S(\%)=100 \times\left(1-\frac{\rho_{\text {resin }}}{\rho_{\text {polymer }}}\right)
$$


In this equation, $\rho_{\text {resin }}$ and $\rho_{\text {polymer }}$ represent respectively the density of the uncured resin and the density of the polymer.

The density of the uncured liquid resin was measured using a pycnometer of known volume by weighing on a balance with a $0.0001 \mathrm{~g}$ accuracy. Three measurements were carried out in order to determine the average density of each uncured formulation.

The density of the polymer, obtained by curing with the LED@ $405 \mathrm{~nm}$, centred at $405 \mathrm{~nm}$ with a half bandwidth (HBW) of $14 \mathrm{~nm}$, having an intensity around $120 \mathrm{~mW} \cdot \mathrm{cm}^{-2}$ at the sample position, was evaluated using the kern density determination kit comprising a hydrostatic balance (accuracy $0.0001 \mathrm{~g}$ ). The solid was weighed in air and immersed in water by referring to the Archimedes principles, the density of the polymer is determined by the Equation (2):

$$
\rho_{\text {polymer }}=\frac{m_{\text {air }} \times d_{\text {water }}}{m_{\text {air }}-m_{\text {water }}}
$$

In this equation, $m_{\text {air }}, d_{\text {water }}$ and $m_{\text {water }}$ are respectively the mass of the polymer in air, the water density and the mass of the polymer in water. Three measurements were carried out in order to determine the average density of each cured formulation.

\subsection{Swelling studies}

The swelling studies on the polymers produced with a three-component photoinitiating systems were performed by immersion in acetonitrile at room temperature. At specific point of time, the polymeric samples were retrieved and the residual acetonitrile at the surface of the samples blotted with paper before weight measurement. The swelling ratio (SR) was calculated using the Equation (3):

$$
S R=\frac{m_{\text {swollen }}-m_{0}}{m_{0}} \times 100
$$

In this equation, $m_{\text {swollen }}$ and $m_{0}$ represent respectively the swollen and initial mass.

In addition to the swelling ratio, the dry weight of the samples was measured by weighing after leaving the swollen samples in an oven at $70{ }^{\circ} \mathrm{C}$ for $24 \mathrm{~h}$.

\subsection{AFM investigation}

AFM measurements were carried out in a Bruker Multimode IV, with a Nanoscope V controller and an E "vertical" scanner, by the Peak Force Quantitative Nanomechanical Mapping (PFQNM, Bruker) method. PF-QNM is a contact AFM mode, based on the force-volume method. In this method, force distance curves are collected by nanoindentation of the sample in a pointby-point mode. During measurement, the maximum (peak force) is controlled at each pixel to obtain force-distance curves which are then used as feedback signal. In this method, the loading and unloading force-distance curves are collected at a frequency of $2 \mathrm{kHz}$ at each position within the mapped area of the specimen. In parallel to topography images, information on material elasticity (Young's modulus), tip-to-surface adhesion were obtained. The modulus distribution for each sample surface was then plotted and fitted with a modified exponential Gaussian law; the reported moduli thus correspond to the centre of the distributions whereas the errors correspond to their widths.

All experiments were carried out in air and at room temperature. $1 \mu \mathrm{m} \times 1 \mu \mathrm{m}(256 \times 256$ pixels at $0.6 \mathrm{~Hz}$ ) were taken at three different areas on the sample surface. To get relevant results, the 
cantilever and the tip geometry are taking into account in the PF-QNM measurements. Thus, a calibration procedure was first followed. All quantitative measurements were carried out with NCLR cantilever (NANO WORLD) with a spring constant of $48 \mathrm{~N} / \mathrm{m}$ and resonance frequency of $160 \mathrm{kHz}$, a width of $38 \mu \mathrm{m}$ and a length of $225 \mu \mathrm{m}$. Thanks to the Sader method (using the length, the width, the resonance frequency and the quality factor of the cantilever) the actual spring constant was determined and found to be around $27 \mathrm{~N} / \mathrm{m}$. Then, the deflection sensitivity (around $37 \mathrm{~nm} / \mathrm{V}$ ) was measured on a sapphire surface. Tip radius was calibrated against a polystyrene standard provided by Bruker. The measured value of the tip radius was $90 \mathrm{~nm}$. The Poisson's ratio was assumed to be equal to 0.3 . For all experiments, samples were previously (at least half a day before) fixed on a sample holder with a double-sided tape.

\section{Results and discussion}

3.1 Light absorption properties of the studied photoinitiators

The ground state absorption spectra of $\mathrm{CuA}, \mathrm{CuB}$ and $\mathrm{G} 1$ in dichloromethane are presented in Figure 1 . These compounds are characterised by a broad and strong absorption band in the near UV spectral region $\left(350-400 \mathrm{~nm}\right.$ ) which extends up to $450 \mathrm{~nm}$. The absorption maxima $\left(\lambda_{\max }\right)$ and the molar extinction coefficients $(\varepsilon)$ for $\lambda_{\max }$ and at $405 \mathrm{~nm}$ which is the LED nominal wavelength are gathered in Table 1. For the three photoinitiators, the absorption maxima ensure a good overlap with the emission spectrum of the violet LED (centered at $405 \mathrm{~nm}$ ) used in this work. The two copper complexes $\mathrm{CuA}$ and $\mathrm{CuB}$ are characterized by rather similar absorption properties to the copper complex G1 which is used as a reference compound $\left(\varepsilon_{405 \mathrm{~nm}}=1.8 \times 10^{3}\right.$, $1.4 \times 10^{3}$ and $1.9 \times 10^{3} \mathrm{~L}_{\mathrm{mol}} \mathrm{m}^{-1} . \mathrm{cm}^{-1}$ respectively).

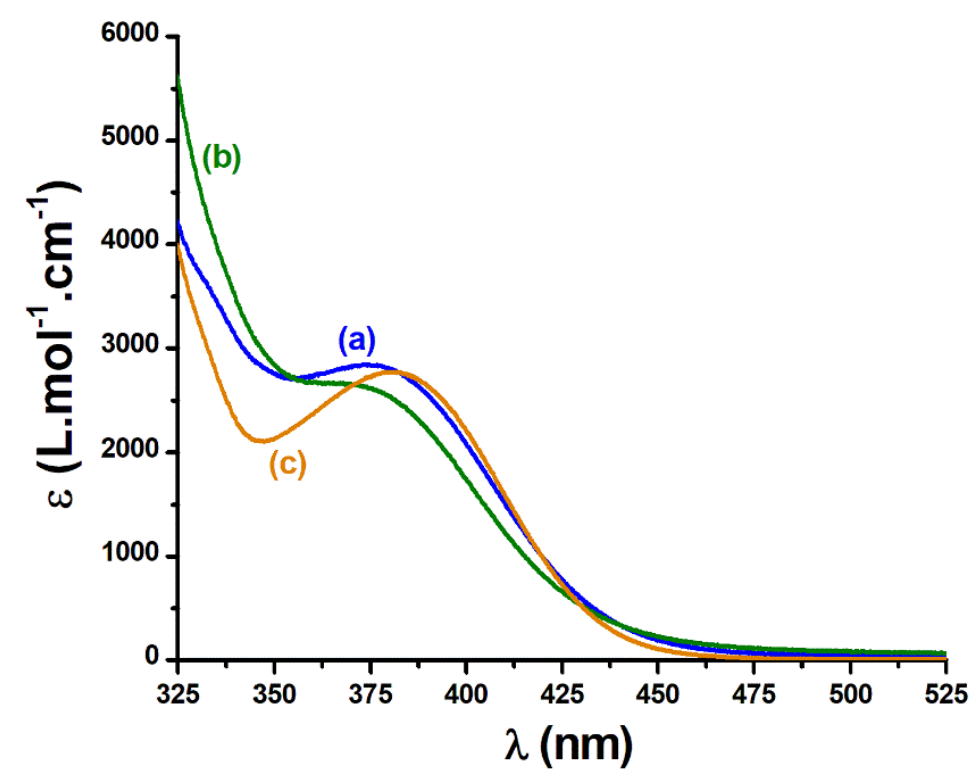

Figure 1: UV-visible absorption spectra of (a) $\mathrm{CuA}$, (b) $\mathrm{CuB}$ and (c) $\mathrm{G} 1$ in dichloromethane

Table 1: Maximum absorption wavelengths $\lambda_{\max }$, extinction coefficients at $\lambda_{\max }$ and at the nominal emission wavelength of the LED (405nm) for $\mathrm{CuA}, \mathrm{CuB}$ and G1 


\begin{tabular}{lccc}
\hline & $\lambda_{\text {max }}(\mathrm{nm})$ & $\varepsilon \lambda_{\max }\left({\left.\mathrm{L} . \mathrm{mol}^{-1} . \mathrm{cm}^{-1}\right)}^{-1}\right.$ & $\varepsilon_{405 \mathrm{~nm}}\left(\mathrm{~L} . \mathrm{mol}^{-1} . \mathrm{cm}^{-1}\right)$ \\
\hline $\mathrm{CuA}$ & 375 & $2.8 \times 10^{3}$ & $1.8 \times 10^{3}$ \\
$\mathrm{CuB}$ & 370 & $2.7 \times 10^{3}$ & $1.4 \times 10^{3}$ \\
$\mathrm{G} 1$ & 380 & $2.8 \times 10^{3}$ & $1.9 \times 10^{3}$
\end{tabular}

\subsection{Fluorescence experiments and reaction pathway}

To assess the properties of the excited state of the investigated copper complexes, a steady state fluorescence analysis was performed. Unfortunately, as presented in Figure 2 with the emission spectra of $\mathrm{CuA}$ and $\mathrm{CuB}$ in dichloromethane, a degradation of the copper complexes was observed after several minutes of analysis under irradiation. This possible photolysis of the copper complexes generates a permanent modification of the excited states and thus the luminescence properties. These facts are in line with the finding of Korn et al [14] which reported an equilibrium in solution between heteroleptic and homoleptic copper complexes through ligand exchange.

(A)



(B)

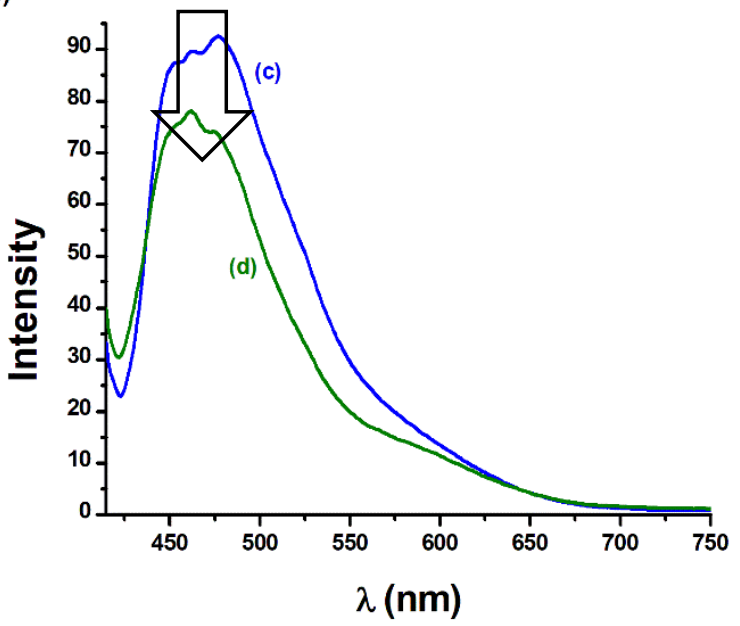

Figure 2 Fluorescence emission spectra in dichloromethane under air $\lambda_{\mathrm{ex}}=405 \mathrm{~nm}$ (A) [CuA] $=4.8 \times 10^{-5} \mathrm{~mol} . \mathrm{L}^{-1}$ (curve a) before photolysis, (curve b) after photolysis; $(\mathrm{B})[\mathrm{CuB}]=4.9$ $\mathrm{x} 10^{-5}$ mol.L $\mathrm{L}^{-1}$ (curve c) before photolysis, (curve d) after photolysis.

Due to the similarity of structure of the copper complexes $\mathrm{CuA}$ and $\mathrm{CuB}$ with the benchmark photoinitiator G1, a similar photoredox catalytic cycle was considered. As depicted in Scheme 4, this catalytic cycle is based on three species: the photoinitiator G1, the iodonium salt $\mathrm{Ar}_{2} \mathrm{I}^{+}$ and the amine EDB. Upon irradiation, the copper complex G1 is excited and reacts with the iodonium salt to generate radicals and $\mathrm{Cu}$ (II) complex noted $\mathrm{G} 1^{+}$via electron transfer reaction. A reaction of the generated radicals with EDB induces the formation of $\mathrm{EDB}_{(-\mathrm{H})}{ }$ which after reaction with $\mathrm{G}^{+}$leads simultaneously to the regeneration of copper complex $\mathrm{G} 1$ and the generation of cation $\mathrm{EDB}^{+}(-\mathrm{H})$ capable of initiating cationic polymerisation. 


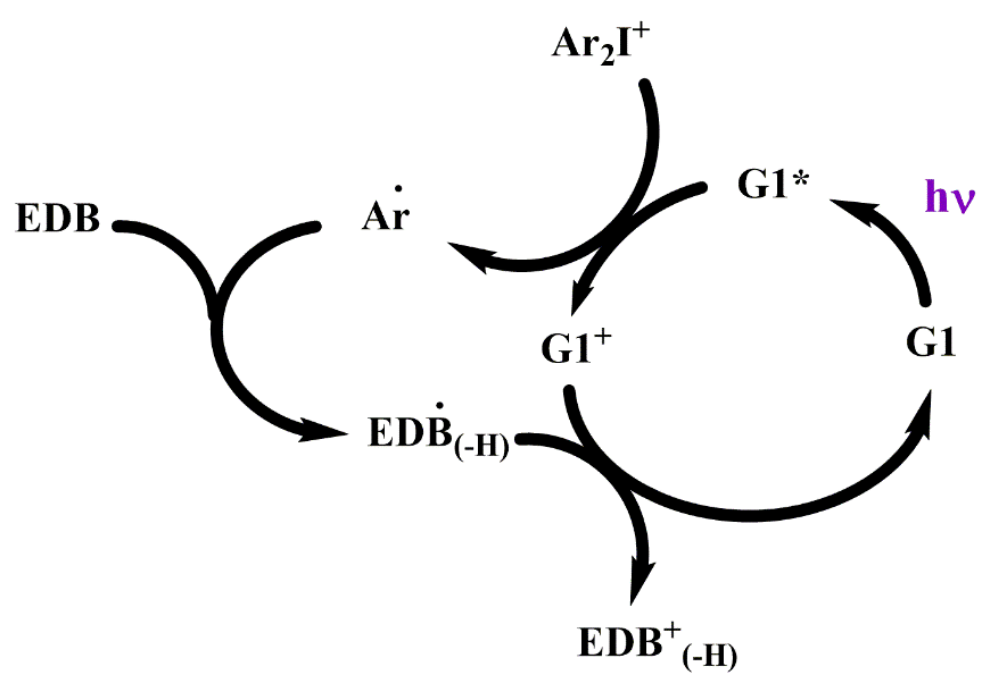

Scheme 4: Photoredox catalytic cycle for the three-component system G1/Iod/EDB - Adapted from [3] [15].

3.3 Experimental approach for the concomitant initiation of the free radical and cationic polymerisation

\subsubsection{Free radical polymerisation}

The free radical polymerisation of TMPTA in the presence of CuA/Iod/EDB and $\mathrm{CuB} / \mathrm{Iod} / \mathrm{EDB}$, was performed under air using a LED emitting at $405 \mathrm{~nm}$. To fully characterise the performance of $\mathrm{CuA}$ and $\mathrm{CuB}$, two photoinitiating systems were used as standards i.e. i) G1/Iod/EDB was used as a reference system to illustrate the performance of one of the best copper complex photoinitiator reported to date and ii) Iod/EDB was also used as a standard since the $\mathrm{N}$-aromatic amine EDB could form a charge transfer complex with the iodonium salt Iod and produce the radical $\mathrm{Ar}_{2} \mathrm{I}^{\circ}$ and the radical-cation $\mathrm{EDB}^{++}$capable to initiate polymerisations [16][17]. Moreover, the concentration of the copper complex photoinitiator is chosen to ensure the same light absorption at $405 \mathrm{~nm}$. The photopolymerisation profiles of TMTPA are presented in Figure 3. Among the tested systems, $\mathrm{CuA} / \mathrm{Iod} / \mathrm{EDB}, \mathrm{CuB} / \mathrm{Iod} / \mathrm{EDB}$ and $\mathrm{G} 1 / \mathrm{Iod} / \mathrm{EDB}$ exhibited similar polymerisation rates and final $\mathrm{C}=\mathrm{C}$ double bond conversions which are higher than those obtained with the reference Iod/EDB system. Indeed, the reaction with $\mathrm{CuA}, \mathrm{CuB}$ or $\mathrm{G} 1$ is really fast, completed in less than 30 s with final conversion around $85 \%$ while the charge transfer complex leads to a final conversion around $65 \%$ after $100 \mathrm{~s}$ of reaction. Therefore, the investigated copper complexes $\mathrm{CuA}$ and $\mathrm{CuB}$ are equivalent to $\mathrm{G} 1$ and highly efficient to initiate the free radical polymerisation. 


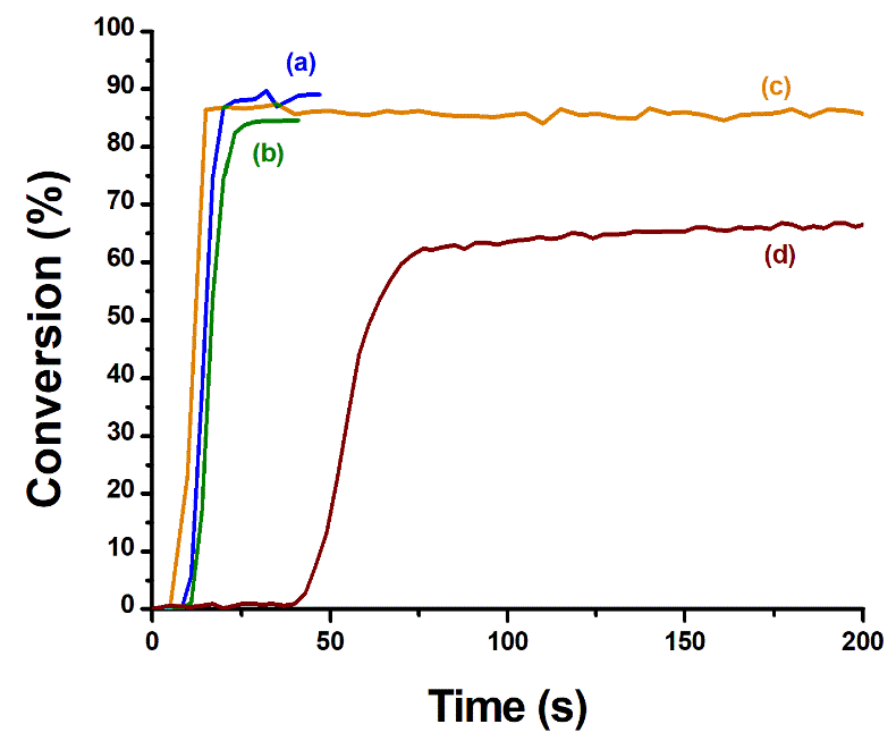

Figure 3: Polymerisation profiles (acrylate function conversion vs irradiation time) of TMPTA upon irradiation with a LED at $405 \mathrm{~nm}$, under air, sample thickness $=1.4 \mathrm{~mm}$, the irradiation starts at $10 \mathrm{~s}, 50 \mathrm{~mW} . \mathrm{cm}^{-2}$. Photoinitiating systems: (curve a) CuA/Iod/EDB (0.39/2.0/2.0 w/w/w\%), (curve b) CuB/Iod/EDB (0.45/2.0/2.0 w/w/w\%), (curve c) G1/Iod/EDB (0.33/2.0/2.0 $\mathrm{w} / \mathrm{w} / \mathrm{w} \%)$ and (curve d) Iod/EDB $(2.0 / 2.0 \mathrm{w} / \mathrm{w} \%)$

\subsubsection{Cationic polymerisation}

The cationic polymerisation of EPOX in the presence of $\mathrm{CuA} / \mathrm{Iod} / \mathrm{EDB}$ and $\mathrm{CuB} / \mathrm{Iod} / \mathrm{EDB}$, was performed under air using a LED centred on $405 \mathrm{~nm}$. Similarly to the free radical polymerisation, two photoinitiating systems were used as standards: G1/Iod/EDB and Iod/EDB. The photopolymerisation profiles of EPOX are presented in Figure 4. Among the tested systems, $\mathrm{CuA} / \mathrm{Iod} / \mathrm{EDB}$ and $\mathrm{CuB} / \mathrm{Iod} / \mathrm{EDB}$ are slightly inferior to the system $\mathrm{G} 1 / \mathrm{Iod} / \mathrm{EDB}$ but better than the standard Iod/EDB system. Indeed, their polymerisation rates and final epoxy group conversions are lower than those obtained for the efficient reference G1/Iod/EDB but higher than those for the system Iod/EDB. However, $\mathrm{CuA}$ and $\mathrm{CuB}$ are still capable to initiate the cationic polymerisation. 


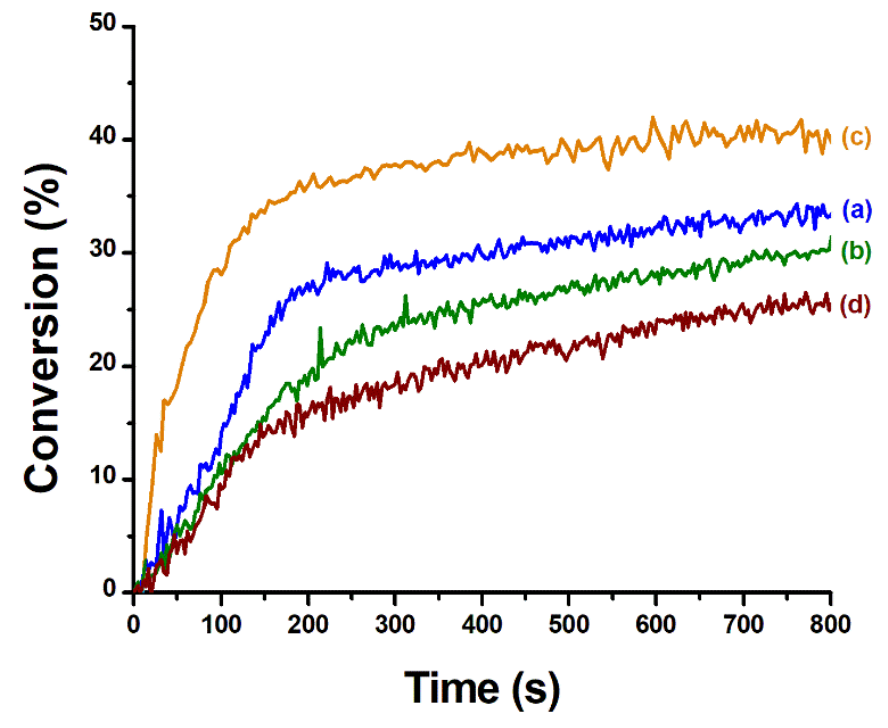

Figure 4: Polymerisation profiles (epoxide function conversion vs irradiation time) of EPOX upon irradiation with a LED at $405 \mathrm{~nm}$, under air, sample thickness $=1.4 \mathrm{~mm}$, the irradiation starts at $10 \mathrm{~s}, 50 \mathrm{~mW} . \mathrm{cm}^{-2}$. Photoinitiating systems: (curve a) CuA/Iod/EDB (0.39/2.0/2.0 w/w/w\%), (curve b) $\mathrm{CuB} / \mathrm{Iod} / \mathrm{EDB}(0.46 / 2.0 / 2.0 \mathrm{w} / \mathrm{w} / \mathrm{w} \%$ ), (curve c) G1/Iod/EDB (0.33/2.0/2.0 $\mathrm{w} / \mathrm{w} / \mathrm{w} \%)$ and (curve d) Iod/EDB $(2.0 / 2.0 \mathrm{w} / \mathrm{w} \%)$

\subsubsection{Interpenetrated polymer networks synthesis}

Interpenetrated polymer networks (IPNs) can be synthesized by initiating concomitantly a free radical and a cationic polymerisation in order to obtain two chemically different interlaced polymer networks which are not covalently bonded. This reaction could be done in one pot by using a photoinitiating system capable of initiating both polymerisation in a blend of TMPTA and EPOX $(50 / 50 \mathrm{w} / \mathrm{w} \%)$. Examples recorded in literature are photoinitiating systems based on G1 [9].

The polymerisation of a TMPTA/EPOX blend in the presence of CuA/Iod/EDB or $\mathrm{CuB} / \mathrm{Iod} / \mathrm{EDB}$, was performed under air using a LED emitting at $405 \mathrm{~nm}$. Again, two photoinitiating systems were used as standards: G1/Iod/EDB and Iod/EDB. The photopolymerisation profiles of the IPN synthesis are presented in Figure 5. Among the tested systems, $\mathrm{CuA} / \mathrm{Iod} / \mathrm{EDB}, \mathrm{CuB} / \mathrm{Iod} / \mathrm{EDB}$ and G1/Iod/EDB exhibited similar polymerisation rates and final $\mathrm{C}=\mathrm{C}$ double bond conversions which are higher than those obtained with the reference $\mathrm{Iod} / \mathrm{EDB}$. Indeed, the formation of the acrylic network with $\mathrm{CuA}, \mathrm{CuB}$ or $\mathrm{G} 1$ is fast, completed in around $50 \mathrm{~s}$ with a final conversion around $88 \%$ while the Iod/EDB charge transfer complex led to a final conversion around $68 \%$ after $400 \mathrm{~s}$ of reaction. Concerning the formation of the epoxy network, both the three-component $\mathrm{CuA} / \mathrm{Iod} / \mathrm{EDB}$ and $\mathrm{CuB} / \mathrm{Iod} / \mathrm{EDB}$ photoinitiating systems led to a higher final epoxy group conversion than the efficient reference system G1/Iod/EDB and the control system Iod/EDB. With the synthesis of IPNs, an increase of the final conversion of both the $\mathrm{C}=\mathrm{C}$ double bond and the epoxy group were observed. This improvement could be related to the synergy between the free radical polymerisation and the cationic polymerisation during the two networks formation. Indeed, under irradiation, the radical polymerisation is at first inhibited by the oxygen in the medium, while the cationic 
polymerisation starts immediately which induces an increase of the medium viscosity limiting the diffusional oxygen replenishment. The cationic monomer also acts as a diluting agent for the radical polymer network allowing to achieve a higher conversion. The exothermic property of the radical polymerisation also tends to boost the cationic polymerisation that is quite temperature sensitive. Thus, the investigated copper complexes $\mathrm{CuA}$ and $\mathrm{CuB}$ are capable to initiate simultaneously the cationic and free radical polymerisations leading to the formation of acrylate/epoxy IPN under visible. Moreover, these two photoinitiating systems led to better results than the corresponding system using the highly efficient photoinitiator G1 (higher final conversion).
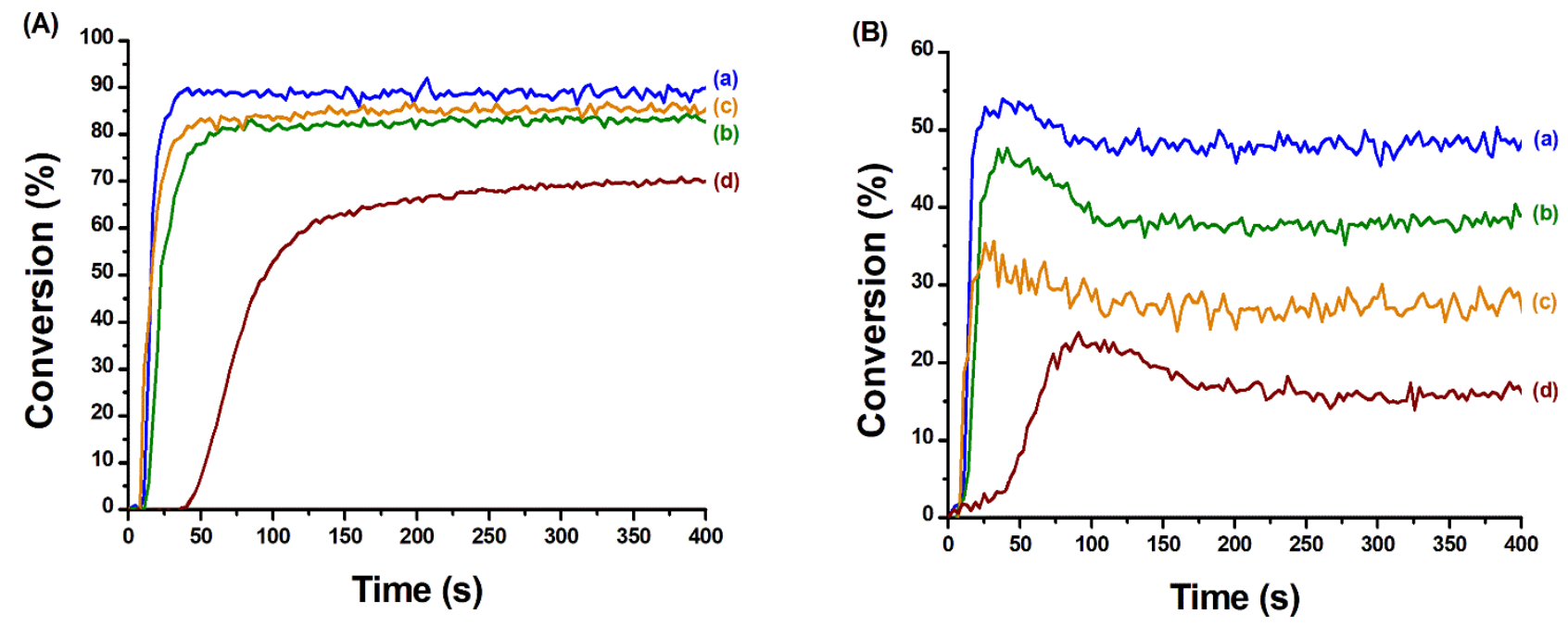

Figure 5: Polymerisation profiles (A) (acrylate function conversion vs irradiation time) and (B) (epoxide function conversion vs irradiation time) of TMPTA/EPOX blend $(50 / 50 \mathrm{w} / \mathrm{w} \%)$ upon irradiation with a LED at $405 \mathrm{~nm}$, under air, sample thickness $=1.4 \mathrm{~mm}$, the irradiation starts at $10 \mathrm{~s}, 50 \mathrm{~mW} . \mathrm{cm}^{-2}$. Photoinitiating systems: (curve a) CuA/Iod/EDB $(0.39 / 2.0 / 2.0 \mathrm{w} / \mathrm{w} / \mathrm{w} \%$ ), (curve b) $\mathrm{CuB} / \mathrm{Iod} / \mathrm{EDB}(0.46 / 2.0 / 2.0 \mathrm{w} / \mathrm{w} / \mathrm{w} \%$ ), (curve c) G1/Iod/EDB (0.33/2.0/2.0 w/w/w\%) and (curve d) Iod/EDB (2.0/2.0 w/w\%)

\subsubsection{Towards higher irradiation wavelength}

According to the UV-visible absorption spectra of $\mathrm{CuA}$ and $\mathrm{CuB}$, the formation of acrylate/epoxy IPN using an irradiation wavelength higher than $405 \mathrm{~nm}$ seems possible. The polymerisation of a TMPTA/EPOX blend $(50 / 50 \mathrm{w} / \mathrm{w} \%)$ in the presence of $\mathrm{CuA} / \mathrm{Iod} / \mathrm{EDB}$ and $\mathrm{CuB} / \mathrm{Iod} / \mathrm{EDB}$, was performed under air using a LED centred on $455 \mathrm{~nm}$. Iod/EDB was used as a standard to ensure that the EDB/Iod charge transfer complex could not initiate the polymerisation under this light. The photopolymerisation profiles of the IPN synthesis are presented in Figure 6. Among the tested systems, both the three-component CuA/Iod/EDB and $\mathrm{CuB} / \mathrm{Iod} / \mathrm{EDB}$ systems allowed the formation of acrylate/epoxy IPN @ $455 \mathrm{~nm}$. However, the performances of the photoinitiating systems are slightly lower under an irradiation at $455 \mathrm{~nm}$ than at $405 \mathrm{~nm}$. Indeed, the final $\mathrm{C}=\mathrm{C}$ double bond conversion is around $80 \%$, the final epoxy group conversion between 20 and 30\%. The formation of the acrylate network and the epoxy network with $\mathrm{CuA}$ or $\mathrm{CuB}$ is also slower around $150 \mathrm{~s}$. The lower performance of the 
photoinitiating system could be explained by the lower absorption of $\mathrm{CuA}$ and $\mathrm{CuB}$ at $455 \mathrm{~nm}$ compared to $405 \mathrm{~nm}$. Therefore, the investigated copper complexes $\mathrm{CuA}$ and $\mathrm{CuB}$ could be used if needed for the polymerisation with a LED centred at $455 \mathrm{~nm}$. Despite this possibility, the commonly used LED centred at $405 \mathrm{~nm}$ was chosen for the rest of this work due to better polymerisation profiles.
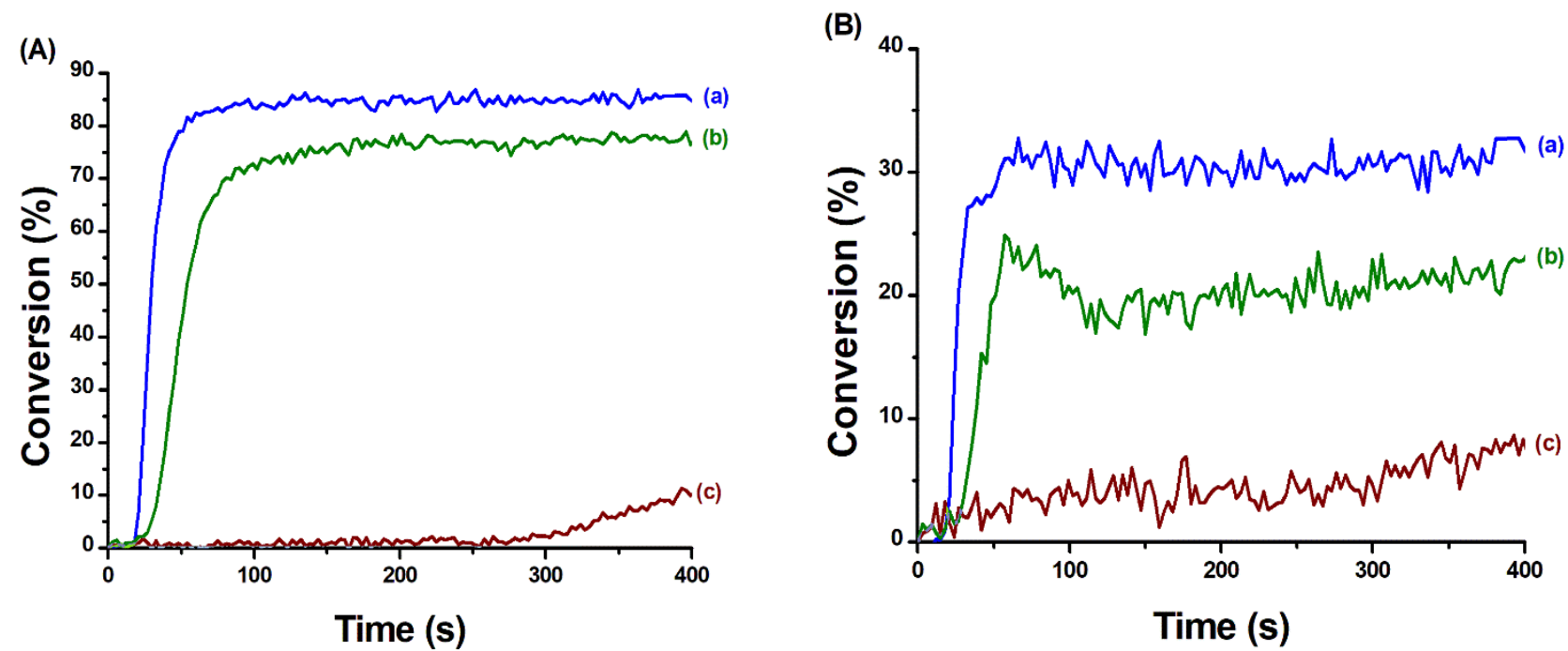

Figure 6: Polymerisation profiles (A) (acrylate function conversion vs irradiation time) and (B) (epoxide function conversion vs irradiation time) of TMPTA/EPOX blend $(50 / 50 \mathrm{w} / \mathrm{w} \%)$ upon irradiation with a LED at $455 \mathrm{~nm}$, under air, sample thickness $=1.4 \mathrm{~mm}$, the irradiation starts at $10 \mathrm{~s}, 50 \mathrm{~mW} . \mathrm{cm}^{-2}$. Photoinitiating systems: (curve a) CuA/Iod/EDB (0.39/2.0/2.0 w/w/w\%), (curve b) CuB/Iod/EDB (0.45/2.0/2.0 w/w/w\%), and (curve c) Iod/EDB (2.0/2.0 w/w\%)

\subsubsection{Effect of the concentration in photoinitiator}

The photoinitiating systems based on $\mathrm{CuA}$ or $\mathrm{CuB}$ were efficient with a relatively high concentration of copper complex (to ensure O.D. $=1$, for a $1.4 \mathrm{~mm}$ thickness sample). However, a reduction of the copper complex concentration while maintaining the performance could be beneficial for considerations such as leaching safety or cost issues. Moreover, since these formulations do not bleach, a reduction of the copper complex concentration could reduce the intensity of the yellow shade of the cured polymers.

The polymerisation of a TMPTA/EPOX blend $(50 / 50 \mathrm{w} / \mathrm{w} \%)$ was performed under air using a LED centred at $405 \mathrm{~nm}$, in the presence of $\mathrm{CuA} / \mathrm{Iod} / \mathrm{EDB}$ and $\mathrm{CuB} / \mathrm{Iod} / \mathrm{EDB}$ with different ratios of copper complex. The photopolymerisation profiles of the IPN synthesis are presented in Figure 7 for $\mathrm{CuA} / \mathrm{Iod} / \mathrm{EDB}$ and in Figure 8 for $\mathrm{CuB} / \mathrm{Iod} / \mathrm{EDB}$. For both systems, decreases of the polymerisation rate, the final $\mathrm{C}=\mathrm{C}$ double bond conversion and the final epoxy group conversion were observed with the decrease of the copper complex concentration. The effect of this decrease is particularly high on the cationic polymerisation. Markedly, the reduction of the copper complexes $\mathrm{CuA}$ and $\mathrm{CuB}$ by 10 times $(0.04 \%$ for $\mathrm{CuA}, 0.05 \%$ for $\mathrm{CuB})$ while maintaining the performance tends to confirm our hypothesis on their reactivity as photocatalyst in a photoredox cycle like G1. 
For the rest of this work, a compromise between the copper complex concentration and the performance of the photoinitiating system were made and the system CuA/Iod/EDB $(0.08 / 2.0 / 2.0 \mathrm{w} / \mathrm{w} / \mathrm{w} \%)$ were chosen i.e. $\mathrm{CuA}$ being more efficient than $\mathrm{CuB}$.
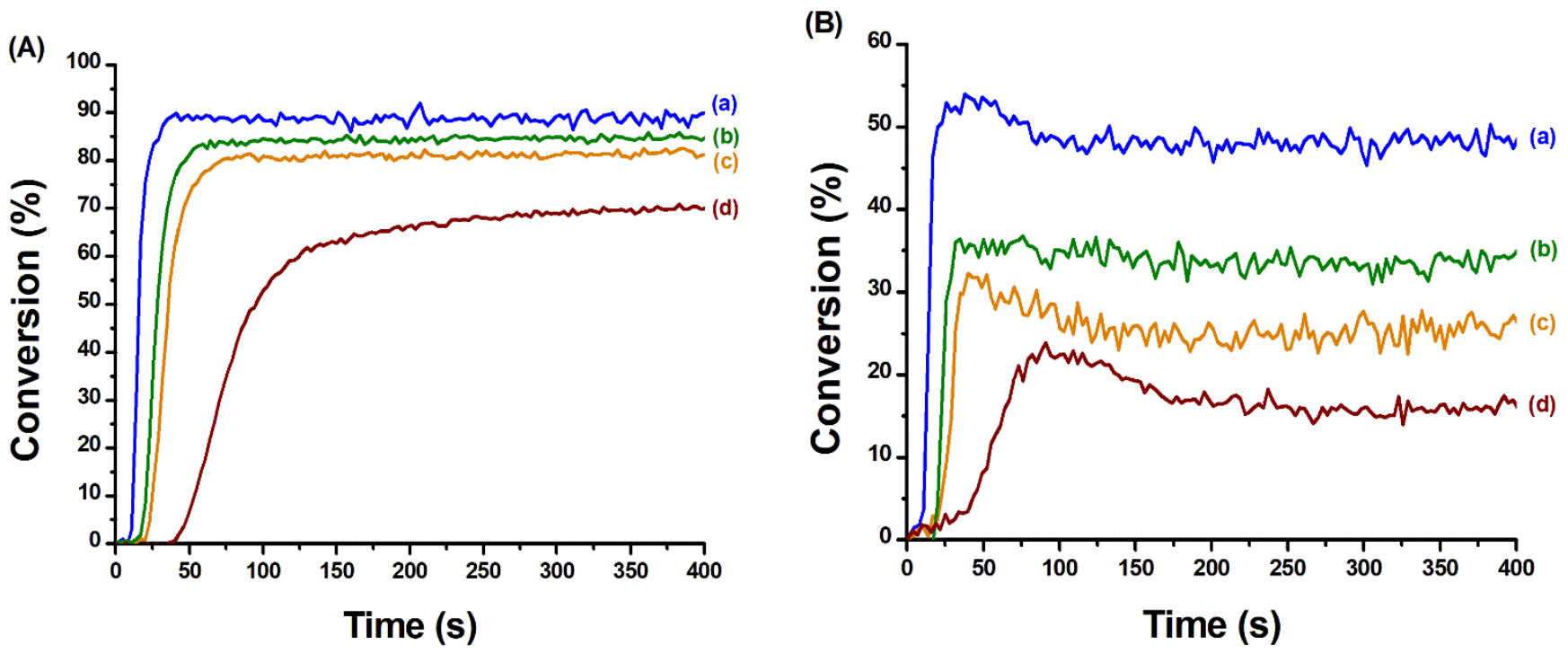

Figure 7: Polymerisation profiles (A) (acrylate function conversion vs irradiation time) and (B) (epoxide function conversion vs irradiation time) of TMPTA/EPOX blend $(50 / 50 \mathrm{w} / \mathrm{w} \%)$ upon irradiation with a LED at $405 \mathrm{~nm}$, under air, sample thickness $=1.4 \mathrm{~mm}$, the irradiation starts at $10 \mathrm{~s}, 50 \mathrm{~mW} . \mathrm{cm}^{-2}$. Photoinitiating systems: (curve a) CuA/Iod/EDB (0.39/2.0/2.0 w/w/w\%), (curve b) $\mathrm{CuA} / \mathrm{Iod} / \mathrm{EDB}(0.08 / 2.0 / 2.0 \mathrm{w} / \mathrm{w} / \mathrm{w} \%$ ), (curve c) $\mathrm{CuA} / \mathrm{Iod} / \mathrm{EDB} \quad(0.04 / 2.0 / 2.0$ $\mathrm{w} / \mathrm{w} / \mathrm{w} \%)$ and (curve d) Iod/EDB $(2.0 / 2.0 \mathrm{w} / \mathrm{w} \%)$
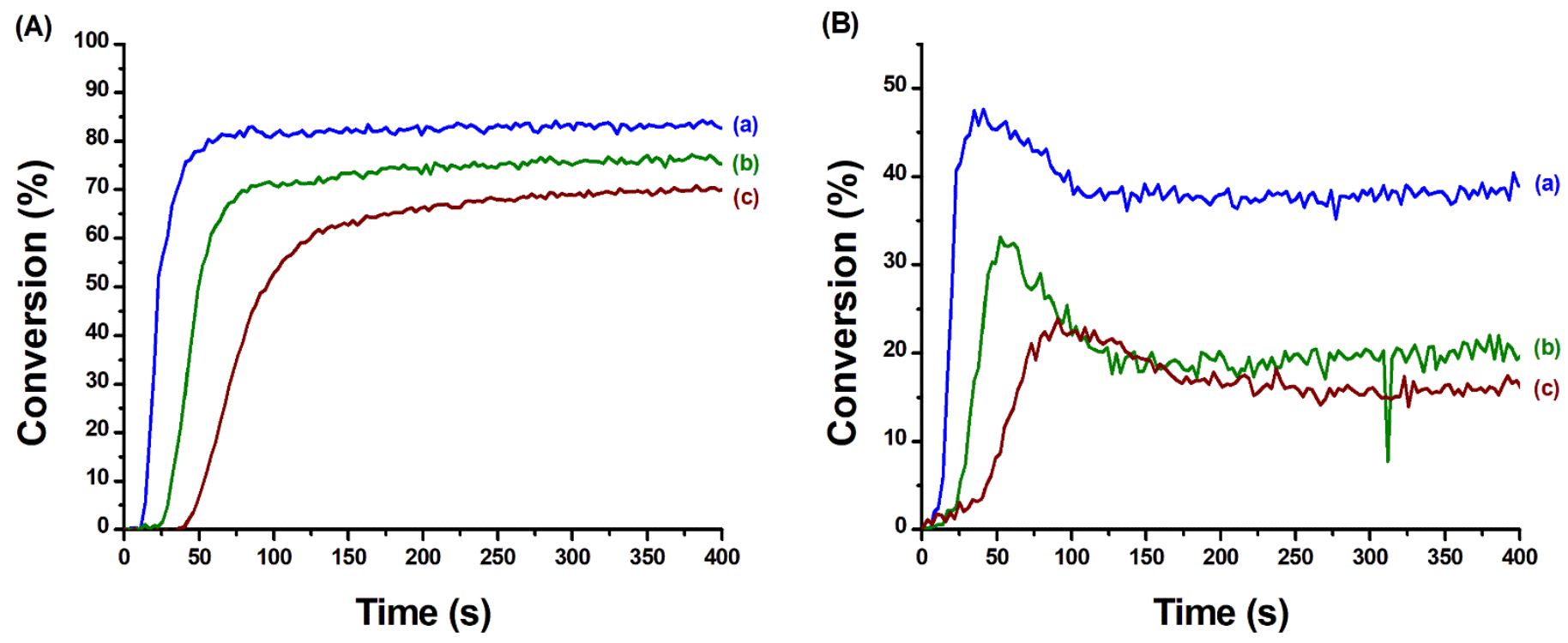

Figure 8: Polymerisation profiles (A) (acrylate function conversion vs irradiation time) and (B) (epoxide function conversion vs irradiation time) of TMPTA/EPOX blend $(50 / 50 \mathrm{w} / \mathrm{w} \%)$ upon irradiation with a LED at $405 \mathrm{~nm}$, under air, sample thickness $=1.4 \mathrm{~mm}$, the irradiation starts 
at $10 \mathrm{~s}, 50 \mathrm{~mW} . \mathrm{cm}^{-2}$. Photoinitiating systems: (curve a) CuB/Iod/EDB (0.42/2.0/2.0 w/w/w\%), (curve b) $\mathrm{CuB} / \mathrm{Iod} / \mathrm{EDB}(0.05 / 2.0 / 2.0 \mathrm{w} / \mathrm{w} / \mathrm{w} \%)$, and (curve c) Iod/EDB (2.0/2.0 w/w\%)

\subsubsection{Effect of the acrylate/epoxy monomer ratio}

The photoinitiating system $\mathrm{CuA} / \mathrm{Iod} / \mathrm{EDB}$ is efficient for the photopolymerisation of different ratios of TMPTA/EPOX blend under exposure to a LED emitting at $405 \mathrm{~nm}$. The final conversions for the epoxy and acrylate functions of the tested blends are given in Table 2. The final conversions were in the same range with all the different ratios of TMPTA and EPOX. The $\mathrm{C}=\mathrm{C}$ double bond conversions ranged from 78 to $90 \%$ and the epoxy group conversion was comprised between 20 and $34 \%$. The polymerisation rate is also similar for IPN TMPTA/EPOX 20/80 (w/w\%), IPN TMPTA/EPOX 50/50 (w/w\%) and IPN TMPTA/EPOX 80/20 (w/w\%) while the polymerisation rate of pure TMPTA was faster. Moreover, no phase separation (turbidity) was observed which suggests a good compatibility of the two networks without obvious microphase separation. Thus, the investigated copper complex $\mathrm{CuA}$ is capable to initiate simultaneously the cationic and free radical polymerisations leading to an efficient formation of acrylate/epoxy IPNs of different ratio under visible light with a single photoinitiating system.

Table 2: Final conversions for the epoxy and acrylate functions (in percentage) obtained under air for $1.4 \mathrm{~mm}$ thickness sample for the photopolymerisation of blends with different ratio between TMPTA and EPOX for $400 \mathrm{~s}$ exposure to LED at $405 \mathrm{~nm}$ in the presence of $\mathrm{CuA} / \mathrm{Iod} / \mathrm{EDB}(0.08 / 2.0 / 2.0 \mathrm{w} / \mathrm{w} / \mathrm{w} \%)$

\begin{tabular}{lll}
\hline Ratio of & & \\
TMPTA / EPOX & TMPTA & EPOX \\
\hline $20 / 80$ & $90 \%$ & $28 \%$ \\
$50 / 50$ & $85 \%$ & $34 \%$ \\
$80 / 20$ & $78 \%$ & $20 \%$ \\
$100 / 0$ & $88 \%$ & - \\
\hline
\end{tabular}

\subsection{Characterisation of the interpenetrated polymer network}

To the best of our knowledge, few characterisations of the IPN final properties are reported in the literature for IPNs synthesised under visible light with a single photoinitiating system to initiate the formation of the two networks.

\subsubsection{Viscoelastic properties of the cured samples}

A dynamic mechanical analysis (DMA) was performed in order to evaluate the mechanical properties of the cured polymers obtained from different blends of TMPTA and EPOX with the photoinitiating system $\mathrm{CuA} / \mathrm{Iod} / \mathrm{EDB}(0.08 / 2.0 / 2.0 \mathrm{w} / \mathrm{w} / \mathrm{w} \%)$ which allows a compromise between the quantity of copper complex and the final conversions of TMPTA and EPOX. Three main characteristics are determined: the storage modulus $\left(G^{\prime}\right)$, the loss modulus $\left(G^{\prime \prime}\right)$ and the damping factor $(\tan \delta)$. The storage modulus corresponds to the elastic component of the sample response to the deformation while the loss modulus corresponds to the viscous one. The damping factor is the ratio of the loss modulus to the storage modulus and corresponds to the capability of the material to dissipate mechanical energy into heat. Through DMA, the glass 
transition temperature $\left(\mathrm{T}_{\mathrm{g}}\right)$ could be determined with several methods. In this work, the $\mathrm{T}_{\mathrm{g}}$ value was defined as the temperature where the damping factor is maximal. The variation of $\tan \delta$ as a function of temperature is depicted in Figure 9A for different ratios of TMPTA/EPOX blends and the corresponding $T_{g}$ value are reported in Table 3. A single $T_{g}$ was detected for the IPN confirming the absence of obvious phase separation between the two polymer networks. A diminution of the $T_{g}$ value was observed with the increase of the EPOX ratio in the blend. Indeed, the epoxide network is by nature more flexible at low temperature than the acrylate network which could explain the lowering of the $\mathrm{T}_{\mathrm{g}}$ value. Moreover, the increase of the EPOX ratio in the blend corresponds to the replacement of trifunctional monomers (TMPTA) by difunctional ones (EPOX). The crosslinking of the IPN is therefore reduced which is another cause of the decrease of the $\mathrm{T}_{\mathrm{g}}$ value. Figure $9 \mathrm{~B}$ and Figure $9 \mathrm{C}$ respectively report the variation of the loss modulus and the storage modulus as a function of temperature. An increase of both moduli was observed with the increase of the content of TMPTA in the blend at high temperature. This reflects the higher degree of crosslinking and consequently a higher mechanical rigidity for the IPN at high temperature. On the contrary at room temperature, an increase of loss modulus was observed with the increase of EPOX content in the blend. An increase of the storage modulus was also observed with the increase of EPOX ratio with the exception of the IPN TMPTA/EPOX 20/80 (w/w\%). Indeed, for this IPN, room temperature corresponds to the glass transition temperature region which explain the strong decrease of storage modulus. Thus, through the modification of the monomer ratio, IPN presenting the mechanical properties could be tuned to correspond to the need of a practical application.

The $\mathrm{T}_{\mathrm{g}}$ of different ratios of TMPTA/EPOX blends were also determined by differential scanning calorimetry and the $T_{g}$ values are reported in Table 3 . Similarly to the $T_{g}$ value measured by DMA, a decrease of $\mathrm{T}_{\mathrm{g}}$ was observed with the increase of the EPOX content. Indeed, in the case of acrylate/epoxy IPN, the $T_{g}$ value is comprised in an interval between the $\mathrm{T}_{\mathrm{g}}$ values of the homopolymers of TMPTA and of EPOX. In the literature, the glass transition temperature of EPOX homopolymers is reported at $-53^{\circ} \mathrm{C}$ [18] while for homopolymers of TMPTA, the reported glass transition temperature is not consistent depending the information source $\left(98^{\circ} \mathrm{C}\right.$ [19]). Since the $\mathrm{T}_{\mathrm{g}}$ value of EPOX is lower than the $\mathrm{T}_{\mathrm{g}}$ value of TMPTA, the increase of the ratio of EPOX in the IPN shifts the $\mathrm{T}_{\mathrm{g}}$ to lower temperature. This characteristic of the IPN is particularly interesting when needing to tune the glass transition of a material. 
(A)

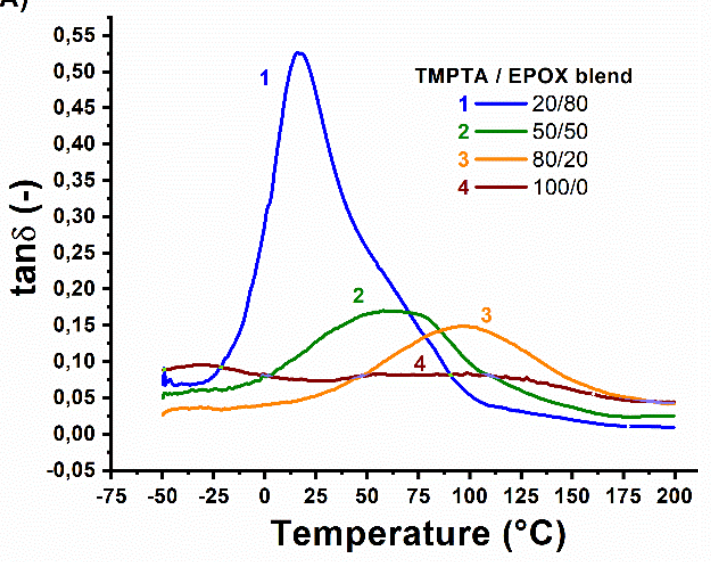

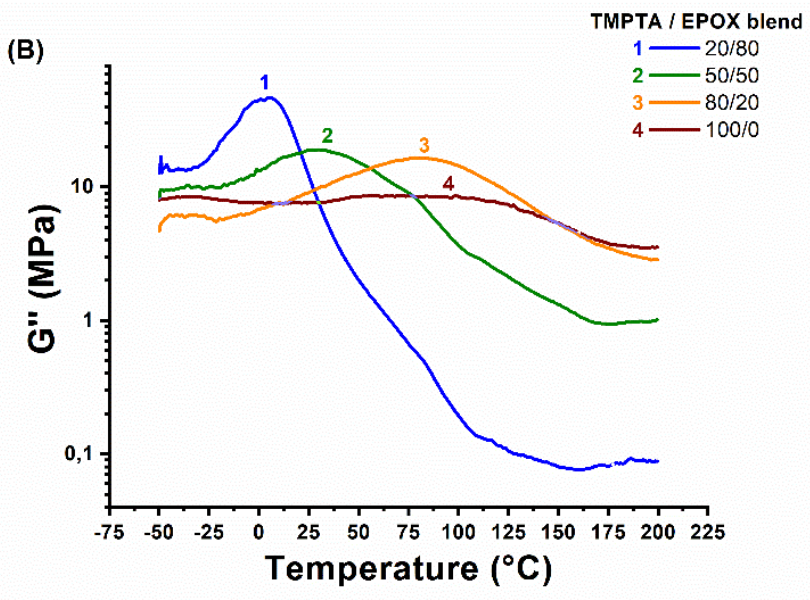

(B)

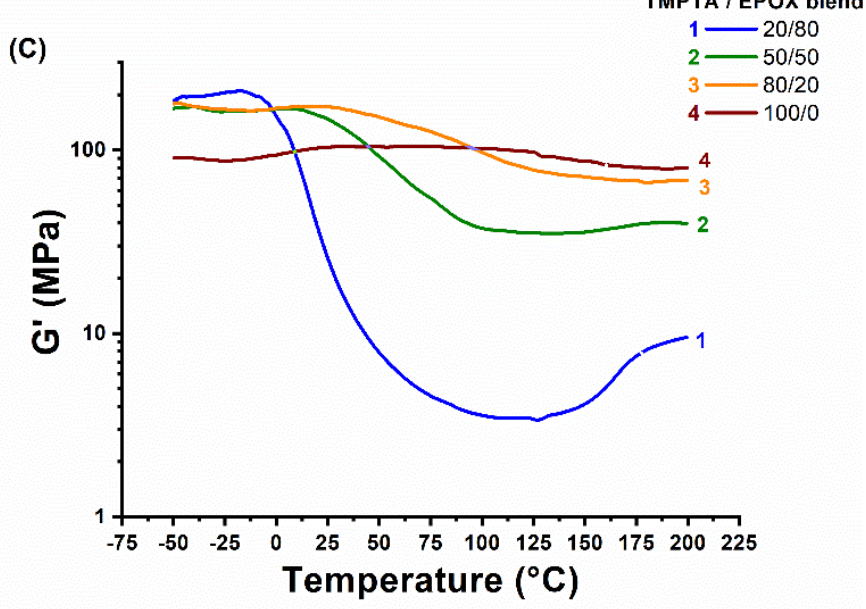

Figure 9: (A) typical tan $\delta$ curves, (B) typical loss modulus curves and (C) typical storage modulus curves for different ratio of TMPTA/EPOX blends as a function of temperature

Table 3 Glass transition temperature $\mathrm{T}_{\mathrm{g}}\left({ }^{\circ} \mathrm{C}\right)$ for the IPN synthetized using blends of different TMPTA/EPOX ratio

\begin{tabular}{lll}
\hline $\begin{array}{l}\text { Ratio of } \\
\text { TMPTA / EPOX }\end{array}$ & $\begin{array}{l}\mathrm{T}_{\mathrm{g}}(\mathrm{DMA}) \\
\left({ }^{\circ} \mathrm{C}\right)\end{array}$ & $\begin{array}{l}\mathrm{T}_{\mathrm{g}}(\mathrm{DSC}) \\
\left({ }^{\circ} \mathrm{C}\right)\end{array}$ \\
\hline $20 / 80$ & 20 & 12 \\
$50 / 50$ & 64 & 33 \\
$80 / 20$ & 97 & 46 \\
$100 / 0$ & - & 81 \\
\hline
\end{tabular}



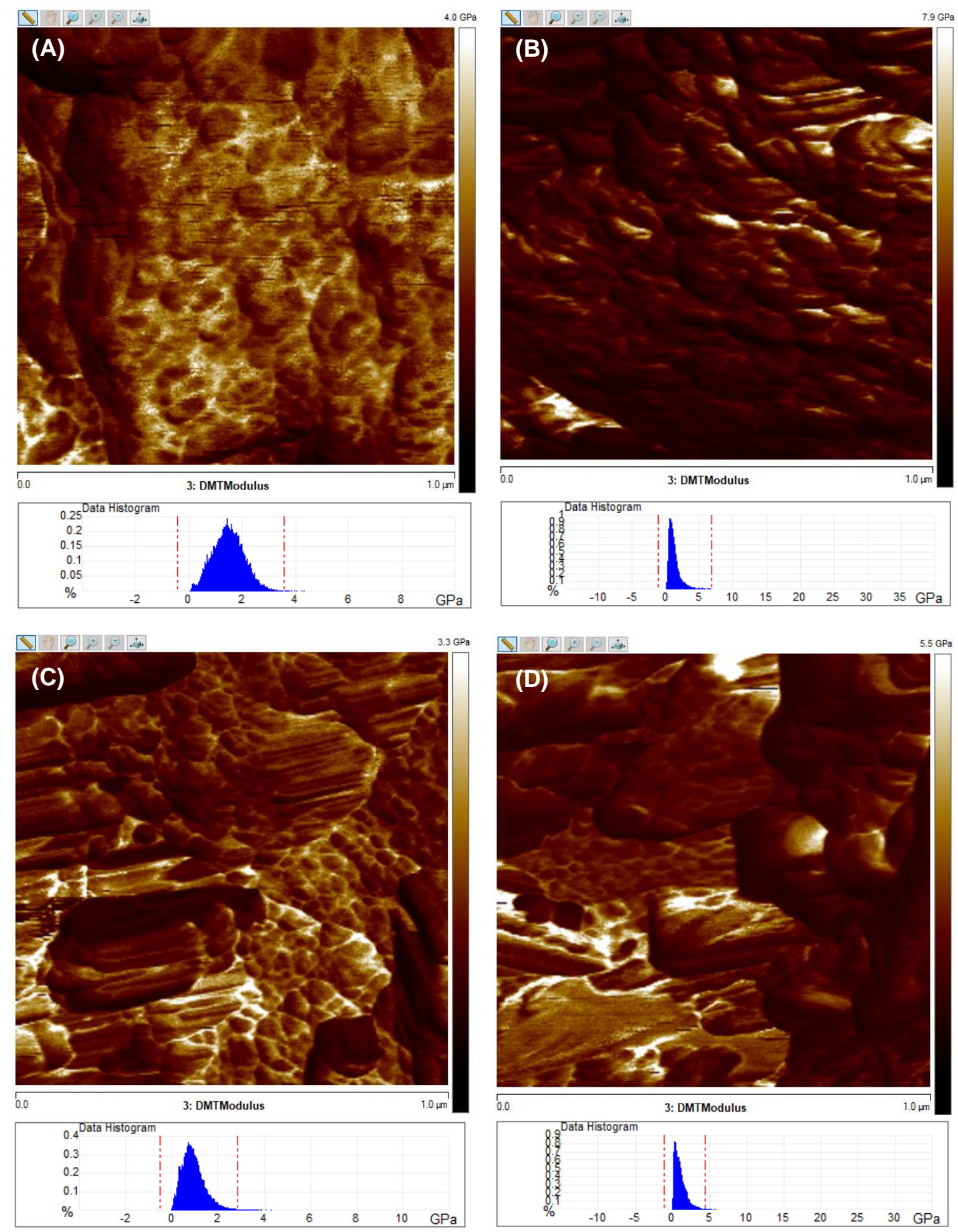

Figure 10: DMT modulus $(1 \mu \mathrm{m} \times 1 \mu \mathrm{m})$ obtained with Peak Force QNM from cured resin after LED irradiation at $405 \mathrm{~nm}$ under air at room temperature in the presence of $\mathrm{CuA} / \mathrm{Iod} / \mathrm{EDB}$ $(0.08 / 2.0 / 2.0 \mathrm{w} / \mathrm{w} / \mathrm{w} \%)$. The different ratio between TMPTA and EPOX in the blends used were: (A) $20 / 80 \mathrm{w} / \mathrm{w} \%$ (B) $50 / 50 \mathrm{w} / \mathrm{w} \%$ (C) $80 / 20 \mathrm{w} / \mathrm{w} \%$ (D) $100 / 0 \mathrm{w} / \mathrm{w} \%$ 
In complement to the characterisation of the mechanical properties of the polymers with different ratios of TMPTA/EPOX, the surface Young moduli of the samples were studied by AFM. The elastic modulus (E) was calculated thanks to the Derjaguin-Müller-Toparov (DMT) fit model. The DMT modulus maps and DMT modulus histograms are presented in Figure 10. The Young modulus was determined Figure 10 as an average value after three measurements per sample thanks to the maps and histograms. The Young modulus values of the tested polymers are reported in Table 4. For the three tested IPNs, this modulus was ranged from 590 $\mathrm{MPa}$ to $1390 \mathrm{MPa}$ and was higher than the one measured for the reference of TMPTA (305 $\mathrm{MPa}$ ). This reflects an increased stiffness in the surface of the IPN compared to TMPTA which could be due to a higher crosslinking on the surface. Indeed, the epoxide network is formed by cationic polymerisation which is not inhibited by oxygen and may allow a higher crosslinking compared to an acrylate network formed by radical polymerisation. However, this modulus does not seem to increase proportionally with of the EPOX content. Moreover, when comparing the Young modulus E to the storage modulus G' obtained by DMA at room temperature (Table 4), a similar evolution of the storage modulus is observed with the increase of EPOX ratio. Indeed, both IPN TMPTA/EPOX 80/20 (w/w\%) and IPN TMPTA/EPOX 50/50 (w/w\%) possessed a higher storage modulus than the reference of TMPTA (respectively $173 \mathrm{MPa}, 154$ MPa and $102 \mathrm{MPa}$ ). The only exception is the IPN TMPTA/EPOX 20/80 (w/w\%) due to the fact that room temperature corresponds to the glass transition temperature region which explain the strong decrease of stiffness and of storage modulus.

Table 4: Young modulus determined by AFM and storage modulus obtained by DMA of the different cured formulation at room temperature

\begin{tabular}{lll}
\hline Ratio of & Young modulus & Storage modulus \\
TMPTA / EPOX & E $(\mathrm{MPa})$ & G' $(\mathrm{MPa})$ \\
\hline $20 / 80$ & 1390 & 36 \\
$50 / 50$ & 590 & 154 \\
$80 / 20$ & 713 & 173 \\
$100 / 0$ & 305 & 102 \\
\hline
\end{tabular}

\subsubsection{Shrinkage}

Shrinkage measurements were carried out for polymers obtained using different blends TMPTA/EPOX with the CuA/Iod/EDB photoinitiating system (with ratios of 20/80, 50/50 and $80 / 20$, respectively). A reference of for pure TMPTA is also given. The volumetric shrinkages (S), reported in Table 5, were determined by measuring the density of the polymer after curing. A decrease of the volumetric shrinkage was observed with the increase of the EPOX content in the monomer blends. Indeed, the presence in the formulation of epoxides induces a slower stiffening of the media during curing due to a slower formation of the epoxide network. The decrease of the volumetric shrinkage during polymerisation involves a reduction of both the internal stress in the polymer and volumetric changes which could be critical when needing a material of precise dimensions e.g. in 3D printing. 


\subsubsection{Adhesion properties}

The adhesion properties of the different polymers were investigated through lap shear strength tests. The different formulations containing blends of TMPTA and EPOX with the photoinitiating system $\mathrm{CuA} / \mathrm{Iod} / \mathrm{EDB}(0.08 / 2.0 / 2.0 \mathrm{w} / \mathrm{w} / \mathrm{w} \%)$ were cured between two epoxy substrates using a LED centred at $405 \mathrm{~nm}\left(\mathrm{I}=120 \mathrm{~mW} \cdot \mathrm{cm}^{-2}\right)$. The bonding of the two epoxy substrates were performed by frontal polymerisation which is a method already described in literature [20] [21]. After $180 \mathrm{~s}$ of irradiation, a successful bonding was observed. The shear stress strengths measured by the dynamometer are reported in Table 5. The introduction of an epoxide network in the IPN TMPTA/EPOX 80/20 (w/w\%) and the IPN TMPTA/EPOX 50/50 (w/w\%) seems to induce the apparition of localised cohesive breaks even though the main mode of breaks is adhesive like for TMPTA. In the case of the IPN TMPTA/EPOX 50/50 (w/w\%), the shear stress strength was even higher than for the reference TMPTA which is interesting when needing to tune the shear resistance of the material. However, for a high EPOX content in the blends such as for IPN TMPTA/EPOX 20/80 (w/w\%), the bonding of the two epoxy substrates is of poor quality possibly due to the presence of residual EPOX monomer due to low epoxy function conversions.

Table 5: Shrinkage value of the cured sample and lap shear strength test results

\begin{tabular}{lccl}
\hline $\begin{array}{l}\text { Ratio of } \\
\text { TMPTA / EPOX }\end{array}$ & $\begin{array}{c}\text { Shrinkage } \\
\text { S }(\%)\end{array}$ & $\begin{array}{c}\text { Shear stress upon } \\
\text { breakage }(\mathrm{MPa})\end{array}$ & break type \\
\hline $20 / 80$ & 5.5 & 0.61 & Bad bonding \\
$50 / 50$ & 9.2 & 2.11 & Mainly adhesive \\
$80 / 20$ & 11.6 & 1.20 & Mainly adhesive \\
$100 / 0$ & 11.8 & 1.83 & Adhesive \\
\hline
\end{tabular}

\subsubsection{Swelling and migration studies}

In order to evaluate the effect of an exposition to solvent on the different polymers, a swelling study was realised in acetonitrile. The cured polymers obtained from different blends of TMPTA and EPOX with the photoinitiating system CuA/Iod/EDB were immersed in acetonitrile for $49 \mathrm{~h}$ at room temperature. The swelling ratio after $24 \mathrm{~h}$ and $49 \mathrm{~h}$ of immersion are presented in Table 6 for the four tested polymers. After 24h, both the IPN TMPTA/EPOX 80/20 $(\mathrm{w} / \mathrm{w} \%)$ and the TMPTA presented a swelling ratio around $0 \%$ which suggested a resistance to acetonitrile. On the contrary, the swelling ratio of the sample IPN TMPTA/EPOX 20/80 (w/w\%) was $-13 \%$ which indicate a loss of mass. The swelling ratio of the sample IPN TMPTA/EPOX 50/50 (w/w\%) was $1 \%$ which indicates a slight swelling. After $49 \mathrm{~h}$, only the reference of TMPTA presented a swelling ratio of $0 \%$ suggesting a resistance to acetonitrile and an absence of swelling. For IPN TMPTA/EPOX 20/80 and IPN TMPTA/EPOX 50/50, a negative swelling ratio was observed and the mass loss seemed to increase with the EPOX ratio in the blends. For the IPN TMPTA/EPOX 80/20 (w/w\%), the swelling ratio increased slightly, from 0 to $1 \%$, but the result remained close to those obtained for the reference TMPTA.

However, concomitantly to the swelling behaviour, a migration of molecules was observed during the immersion in acetonitrile which could result to an undervaluation of the swelling ratio. In order to evaluate the mass loss, the polymers were heated after swelling at $70^{\circ} \mathrm{C}$ for $24 \mathrm{~h}$ in an oven and the dry matter content was determined (Table 6). A mass loss was observed 
for each sample (dry matter content inferior to 100\%). The reference TMPTA and the IPN TMPTA/EPOX 80/20 (w/w\%) presented the same dry matter content. The slight difference in swelling ratio is therefore purely due to the swelling phenomenon. For the two other IPNs, the dry matter content is inferior to the reference TMPTA confirming the important mass loss hinted by the negative swelling ratio.

According to the UV-visible absorption spectra of the acetonitrile solvent used for the swelling experiment, only a migration of the amine EDB was detected which indicated that neither the copper complex $\mathrm{CuA}$ nor the iodonium salt Iod were released. This result is coherent with the low mass loss of TMPTA and IPN TMPTA/EPOX 80/20 (w/w\%). For the IPN TMPTA/EPOX 50/50 (w/w\%) and IPN TMPTA/EPOX 20/80 (w/w\%), the higher mass losses could be explained by the migration of residual monomer in accordance with the lower final conversion for the epoxy function. Thus, the IPN TMPTA/EPOX 80/20 (w/w\%) is similar to the reference TMPTA, a material with a low swelling and a low migration while immersed in acetonitrile.

Table 6: Swelling ratio of cured blends with different ratio between TMPTA and EPOX after $49 \mathrm{~h}$ in acetonitrile and dry matter content

\begin{tabular}{|c|c|c|c|}
\hline $\begin{array}{l}\text { Ratio of } \\
\text { TMPTA / EPOX }\end{array}$ & $\begin{array}{l}\text { Swelling ratio } \\
\text { SR after } 24 \mathrm{~h}(\mathrm{w} \%)\end{array}$ & $\begin{array}{l}\text { Swelling ratio } \\
\text { SR after } 49 \mathrm{~h}(\mathrm{w} \%)\end{array}$ & $\begin{array}{l}\text { dry matter content } \\
(\mathrm{w} \%)\end{array}$ \\
\hline $20 / 80$ & -13 & -16 & 61 \\
\hline $50 / 50$ & 1 & -2 & 85 \\
\hline $80 / 20$ & 0 & 1 & 99 \\
\hline $100 / 0$ & 0 & 0 & 99 \\
\hline
\end{tabular}

\section{Conclusion}

In the present paper, two new copper complexes $\mathrm{CuA}$ and $\mathrm{CuB}$ were studied as photoinitiators in a three component photoinitiating system $\mathrm{Cu} / \mathrm{Iod} / \mathrm{EDB}$. These two copper complexes were capable to efficiently initiate both the radical and cationic polymerisations and exhibited similar performances than the benchmark system G1/Iod/EDB based on an outstanding copper complex G1. The formation of acrylate/epoxy IPNs were successfully performed through the concomitant initiation of both radical and cationic polymerisations for $1.4 \mathrm{~mm}$ thick samples under air upon irradiation @ $405 \mathrm{~nm}$ with a low quantity of copper complex. The synthesis of acrylate/epoxy IPN upon irradiation @455 nm was also possible. Several characterisations of the IPNs final properties, such as the mechanical properties, adhesion properties, shrinkage and swelling, indicated the possibilities to tune their properties compared to pure TMPTA using an appropriated ratio of monomer blend. Characterisation of IPNs for other synthetic conditions will be done in following works with example in application (e.g. 3D printing) where the advantage of IPN can be worthwhile (e.g. to reduce the shrinkage).

\section{Conflicts of interest}

There are no conflicts to declare. 


\section{Acknowledgements}

The Agence Nationale de la Recherche (ANR agency) is thanked for the funding of the VISICAT project (ANR-17-CE08-0054) 


\section{References}

[1] J. Kirschner, F. Szillat, M. Bouzrati-Zerelli, J.-M. Becht, J.E. Klee, J. Lalevée, Iodonium sulfonates as high-performance coinitiators and additives for CQ-based systems: Toward aromatic amine-free photoinitiating systems, J. Polym. Sci. Part Polym. Chem. 57 (2019) 1664-1669. https://doi.org/10.1002/pola.29431.

[2] J. Lalevée, J.P. Fouassier, B. Graff, J. Zhang, P. Xiao, Chapter 6:How to Design Novel Photoinitiators for Blue Light, in: Photopolymerisation Initiat. Syst., 2018: pp. 179-199. https://doi.org/10.1039/9781788013307-00179.

[3] H. Mokbel, D. Anderson, R. Plenderleith, C. Dietlin, F. Morlet-Savary, F. Dumur, D. Gigmes, J.-P. Fouassier, J. Lalevée, Copper photoredox catalyst "G1": a new high performance photoinitiator for near-UV and visible LEDs, Polym. Chem. 8 (2017) 55805592. https://doi.org/10.1039/C7PY01016H.

[4] S.C. Ligon, R. Liska, J. Stampfl, M. Gurr, R. Mülhaupt, Polymers for 3D Printing and Customized Additive Manufacturing, Chem. Rev. 117 (2017) 10212-10290. https://doi.org/10.1021/acs.chemrev.7b00074.

[5] C. Mendes-Felipe, J. Oliveira, I. Etxebarria, J.L. Vilas-Vilela, S. Lanceros-Mendez, Stateof-the-Art and Future Challenges of UV Curable Polymer-Based Smart Materials for Printing Technologies, Adv. Mater. Technol. 4 (2019) 1800618. https://doi.org/10.1002/admt.201800618.

[6] J. Lalevée, N. Blanchard, M.-A. Tehfe, M. Peter, F. Morlet-Savary, D. Gigmes, J.P. Fouassier, Efficient dual radical/cationic photoinitiator under visible light: a new concept, Polym. Chem. 2 (2011) 1986-1991. https://doi.org/10.1039/C1PY00140J.

[7] S. Telitel, J. Lalevée, N. Blanchard, T. Kavalli, M.-A. Tehfe, S. Schweizer, F. MorletSavary, B. Graff, J.-P. Fouassier, Photopolymerization of Cationic Monomers and Acrylate/Divinylether Blends under Visible Light Using Pyrromethene Dyes, Macromolecules. 45 (2012) 6864-6868. https://doi.org/10.1021/ma301293m.

[8] M.-A. Tehfe, F. Dumur, P. Xiao, M. Delgove, B. Graff, J.-P. Fouassier, D. Gigmes, J. Lalevée, Chalcone derivatives as highly versatile photoinitiators for radical, cationic, thiol-ene and IPN polymerization reactions upon exposure to visible light, Polym. Chem. 5 (2013) 382-390. https://doi.org/10.1039/C3PY00922J.

[9] P. Xiao, F. Dumur, J. Zhang, J.P. Fouassier, D. Gigmes, J. Lalevée, Copper Complexes in Radical Photoinitiating Systems: Applications to Free Radical and Cationic Polymerization upon Visible LEDs, Macromolecules. 47 (2014) 3837-3844. https://doi.org/10.1021/ma5006793.

[10] L.H. Sperling, An Introduction to Polymer Networks and IPNs, in: L.H. Sperling (Ed.), Interpenetr. Polym. Netw. Relat. Mater., Springer US, Boston, MA, 1981: pp. 1-10. https://doi.org/10.1007/978-1-4684-3830-7_1.

[11] M. Sangermano, W. Carbonaro, G. Malucelli, A. Priola, UV-Cured Interpenetrating Acrylic-Epoxy Polymer Networks: Preparation and Characterization, Macromol. Mater. Eng. 293 (2008) 515-520. https://doi.org/10.1002/mame.200800020.

[12] V. Hebbe-Viton, V. Desvergnes, J. J. Jodry, C. Dietrich-Buchecker, J-P. Sauvage, J. Lacour, Chiral spiro $\mathrm{Cu}(\mathrm{I})$ complexes. Supramolecular stereocontrol and isomerisation dynamics by the use of TRISPHAT anions, Dalton Trans. (2006) 2058-2065. 
[13] C. Dietlin, S. Schweizer, P. Xiao, J. Zhang, F. Morlet-Savary, B. Graff, J.-P. Fouassier, J. Lalevée, Photopolymerization upon LEDs: new photoinitiating systems and strategies, Polym. Chem. 6 (2015) 3895-3912. https://doi.org/10.1039/C5PY00258C.

[14] M. Knorn, T. Rawner, R. Czerwieniec, O. Reiser, [Copper(phenanthroline)(bisisonitrile)]+-Complexes for the Visible-Light-Mediated Atom Transfer Radical Addition and Allylation Reactions, ACS Catal. 5 (2015) 51865193. https://doi.org/10.1021/acscatal.5b01071.

[15] M. Bouzrati-Zerelli, N. Guillaume, F. Goubard, T.-T. Bui, S. Villotte, C. Dietlin, F. Morlet-Savary, D. Gigmes, J.P. Fouassier, F. Dumur, J. Lalevée, A novel class of photoinitiators with a thermally activated delayed fluorescence (TADF) property, New J. Chem. 42 (2018) 8261-8270. https://doi.org/10.1039/C7NJ04394E.

[16] P. Garra, B. Graff, F. Morlet-Savary, C. Dietlin, J.-M. Becht, J.-P. Fouassier, J. Lalevée, Charge Transfer Complexes as Pan-Scaled Photoinitiating Systems: From $50 \mu \mathrm{m}$ 3D Printed Polymers at $405 \mathrm{~nm}$ to Extremely Deep Photopolymerization $(31 \mathrm{~cm})$, Macromolecules. 51 (2018) 57-70. https://doi.org/10.1021/acs.macromol.7b02185.

[17] D. Wang, A. Arar, P. Garra, B. Graff, J. Lalevée, Charge Transfer Complexes based on Various Amines as Dual Thermal and Photochemical Polymerization Initiators: A Powerful Tool for the Access to Composites, J. Polym. Sci. 58 (2020) 811-823. https://doi.org/10.1002/pol.20190248.

[18] T. Dollase, T. Krawinkel, M. BAI, Adhesive substance, in particular for encapsulating an electronic assembly, WO2013057265A1, 2013. https://patents.google.com/patent/WO2013057265A1/en (accessed March 9, 2021).

[19] T. Hanemann, K. Honnef, Optical and Thermomechanical Properties of Doped Polyfunctional Acrylate Copolymers, Polymers. 10 (2018) 337. https://doi.org/10.3390/polym10030337.

[20] H. Mokbel, F. Dumur, J. Lalevée, On demand NIR activated photopolyaddition reactions, Polym. Chem. 11 (2020) 4250-4259. https://doi.org/10.1039/D0PY00639D.

[21] W. Zhang, S. Yang, C.-F. Wang, S. Chen, Anisotropic Biphase Frontal Polymerization toward in Situ Generation of Dual-Component Polymers, Macromolecules. 48 (2015) 5543-5549. https://doi.org/10.1021/acs.macromol.5b00659. 


\section{TOC Graph:}

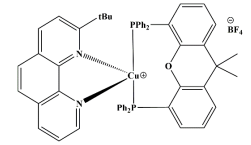

Preparation and characterization of IPNs synthesized in mild conditions using Copper complexes

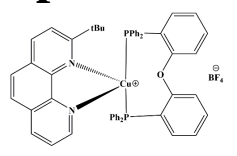

Cus

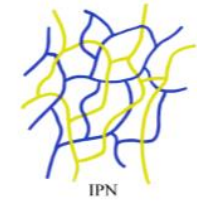

